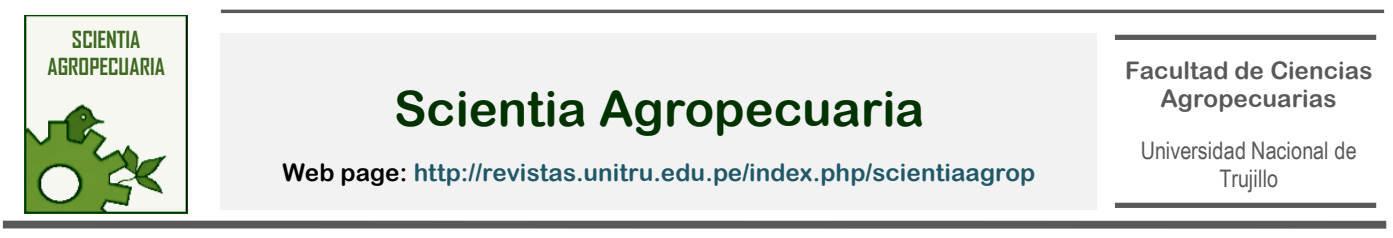

\title{
REVIEW
}

\section{Microalgal biomass with high potential for the biofuels production}

\author{
Biomasa microalgal con alto potencial para la producción de biocombustibles

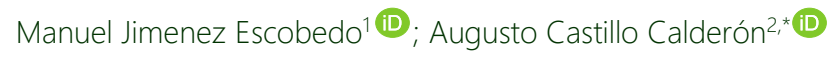
Departamento Académico de Ingeniería Química y Metalúrgica; Universidad Nacional José Faustino Sánchez Carrión; Av. Mercedes Indacochea N. ${ }^{\circ}$ 609, Huacho, Lima. Peru.
2 Departamento Académico de Agroindustria y Agronomía; Universidad Nacional del Santa; Av. Universitaria s/n Urb. Bellamar, Nuevo Chimbote, Ancash. Peru.

*Corresponding author: acastillo@uns.edu.pe (A. Castillo).

Received: 18 October 2020. Accepted: 12 April 2021. Published: 1 June 2021.

\begin{abstract}
The study of biofuels continues in constant development, for five decades. This article summarizes the analysis of several recent scientific publications, related to third generation biofuels using microalgae. An overview of biofuels and their classification, the theoretical bases of microalgae, techniques for their cultivation, harvesting and pretreatment of their biomass are presented. Promising technologies for obtaining biofuels of great potential worldwide demand are also briefly described, considering the technical characteristics of the process, depending on the microalgae species that have the highest yields and productivity for each type of biofuel: Biodiesel (extraction of lipids, transesterification and purification), ethanol (hydrolysis of sugars, fermentation and purification) and biogas (anaerobic digestion). Most studies are focused on the production of lipids, being Chlorella vulgaris, Nanochloropsis sp. and Botryococcus braunii (A) the most used microalgae to obtain biodiesel. However, there are few studies focused on the production of microalgal biomass to produce bioethanol, thus, the microalgae Porphyridium cruentum and Spirogira sp. they could be used to produce bioethanol, with the advantage of not containing lignin. Biogas is produced by anaerobic biodigestion of microalgal biomass residues in biorefineries, but its commercial production is very limited due to high production costs and because there are other economically very competitive biomasses. The need to produce biofuels using microalgal biomass is reaching a greater boom, the transcendental proposal being the launching of a biorefinery, mainly focused on the optimal production of microalgal biomass as the main key to the entire process.
\end{abstract}

Keywords: microalgae; photosynthesis; biofuels; pretreatment; hydrolysis; bioethanol; biorefinery.

\section{Resumen}

El estudio de los biocombustibles sigue en constante desarrollo, desde hace cinco décadas. Este artículo resume el análisis de diversas publicaciones científicas recientes, relacionadas con biocombustibles de tercera generación utilizando microalgas. Se presenta una visión general de biocombustibles y su clasificación, las bases teóricas de microalgas, técnicas para su cultivo, cosecha y pretratamiento de su biomasa. También se describen brevemente tecnologías prometedoras para obtener biocombustibles de gran demanda potencial mundial, considerando las características técnicas del proceso, en función de las especies de microalgas que tienen los más altos rendimientos y productividades para cada tipo de biocombustible: Biodiesel (extracción de lípidos, transesterificación y purificación), etanol (hidrólisis de azúcares, fermentación y purificación) y biogás (digestión anaerobia). La mayoría de los estudios están enfocados en la producción de lípidos, siendo Chlorella vulgaris, Nanochloropsis sp. y Botryococcus braunii (A) las microalgas más utilizadas para obtener biodiesel. Sin embargo, existen pocos estudios centrados en la producción de biomasa microalgal para producir bioetanol, así, las microalgas Porphyridium cruentum y Spirogira sp. podrían utilizarse para producir bioetanol, con la ventaja de no contener lignina. El biogás se produce por biodigestión anaeróbica de los residuos de biomasa microalgal en biorrefinerías, pero su producción comercial está muy limitada por los altos costos productivos y porque existen otras biomasas muy competitivas económicamente. La necesidad de producir biocombustibles utilizando biomasa microalgal, está alcanzando un mayor auge, siendo la propuesta trascendental, poner en marcha una biorrefinería, principalmente enfocada en la producción optima de biomasa microalgal como la clave principal de todo el proceso.

Palabras clave: microalgas; fotosíntesis; biocombustibles; pretratamiento; hidrólisis; bioetanol; biorrefinería.

DOI: https://dx.doi.org/10.17268/sci.agropecu.2021.030

Cite this article:

Jimenez Escobedo, M., \& Castillo Calderón, A. (2021). Biomasa microalgal con alto potencial para la producción de biocombustibles. Scientia Agropecuaria, 12(2), 265-282. 


\section{Introducción}

La demanda energética es un gran desafío para el crecimiento económico combinado con un aumento constante de la población mundial, que proviene principalmente de combustibles fósiles de naturaleza agotable, situación preocupante para el futuro escenario de la energía global, por el creciente consumo y precios elevados, también por los diversos problemas ambientales generados (Bibi et al., 2017). Esta última década fue de vital importancia al retomar y profundizar investigaciones para obtener biocombustibles (biodiesel, bioetanol, biogas, etc.) de diversas fuentes renovables (Odjadjare et al., 2015; Khan et al., 2018; Bader et al., 2020), para reducir el consumo de combustibles fósiles, mitigar el impacto ambiental al disminuir las emisiones de gases de efecto invernadero (Aro, 2016). Estas investigaciones emplean microalgas, microorganismos unicelulares y fotosintéticos, como herramientas biotecnológicas para obtener biocombustibles, y bioproductos, con beneficios adicionales y aplicaciones diversificadas (Tiwari et al., 2019). Las microalgas, dependiendo de la especie y condiciones de cultivo, tienen una rápida producción de biomasa comparada con otros cultivos energéticos, es una alternativa ingenieril para obtener biodiésel por su alto contenido de lípidos y aceites (Mathimani et al., 2015; Fan et al., 2020), como también para producir azúcares fermentables y viabilizar la obtención de bioetanol (Jeong et al., 2020; Bader et al., 2020). Además, la extracción de lípidos genera residuos, contiene nitrógeno y fósforo, que puede reusarse nuevamente como sustrato de las microalgas y procesarse para producir metano mediante digestión anaerobia, que contribuye a alcanzar un equilibrio económico del proceso en una biorrefinería (Martins et al., 2018).

En la producción de biocombustibles, son evaluados diversos factores: caracterización de la cepa de microalgas, mecanismo metabólico, el cultivo en un medio fluido y la velocidad de producción de biomasa, cosecha y pretratamiento de la biomasa, hidrólisis, diseño del fotobiorreactor, el posprocesamiento, etc. (Singh et al., 2017; Shokrkar et al., 2018; Enamala et al., 2018). El proceso tiene una serie de ventajas: la producción primaria es controlable en el laboratorio, altamente escalable, posee balance energético muy positivo, captura y recicla $\mathrm{CO}_{2}$ para aumentar su tasa de crecimiento y proporcionar la capacidad de modificar su composición bioquímica a través de la modificación de la composición de su medio de cultivo, no requiere grandes áreas para el cultivo extensivo, no compiten con la seguridad alimentaria, no dependen de insumos agrícolas ni pesticidas, no contamina el suelo ni afluentes de agua (Khan et al., 2018; Tiwari et al., 2019; Mat Aron et al., 2020). La producción de biocombustibles, utilizando microalgas, como una gran promesa de suministro energético enfrenta muchos desafíos para ser económicamente competitivo (Préat et al., 2020). Desde décadas recientes, se desarrollan intensamente diversas tecnologías de biorrefinería microalgal (procesos químicos, bioquímicos, termoquímicos, etc.) para obtener una viabilidad económica de todo el proceso integrado, producción de biocombustibles y extracción de diversos bioproductos de alto valor agregado desde la biomasa algal (Khoo et al., 2019; Fan et al., 2020). Actualmente están estudiándose procesos productivos a base de diversas especies de algas y microalgas, como la producción a pequeña escala de biodiésel hidrogenado, éter de dimetilo y del gas natural biosintético (Das \& Varanasi, 2019).

Por tanto; lograr la viabilidad de la industria de biocombustibles, a partir de algas, nos conduce a estudiar nuevos y prometedores procesos tecnológicos de biorrefinería, con insumos no relacionados a cultivos de alimentos y que puedan desarrollarse en tierras no ligadas a la agricultura, que ofrezcan nuevas oportunidades para valorizar la biomasa algal, y desarrollar la síntesis de una gran variedad de productos derivados.

\section{Los biocombustibles: una visión general}

La civilización humana, desde sus inicios, utiliza biocombustibles sólidos como la madera, el carbón, el estiércol de vaca, etc., para cocinar y calentar (Webb \& Coates, 2012). En la primera revolución industrial, el aceite de oliva y de ballena, fueron usados para iluminación. En 1826 fue diseñado el primer motor de combustión interna, que funcionó con una mezcla de etanol y trementina, y el primer motor Diesel que funcionó en 1897 con aceite vegetal (Mussatto et al., 2010; Webb, 2016). Luego, los combustibles a base de carbón dominaron como fuente primaria de energía, por ser más eficientes y baratos que los biocombustibles, estos tenían serias desventajas por su tediosa tecnología de conversión y alto precio. La mayor oferta económica de combustibles fósiles, queroseno principalmente, condujo a una fuerte disminución del uso y producción de biocombustibles (Webb \& Coates, 2012). Durante la Primera Guerra Mundial, la escasez de combustibles fósiles devolvió la demanda de bioetanol. En la década de 1970, la grave crisis del petróleo provocó un renovado interés en los biocombustibles como fuentes alternativas, Estados Unidos y Brasil comenzaron a producir bioetanol y biodiésel, a gran escala, para ser utilizados en el transporte, empleando masivamente cultivos alimentarios como la caña de azúcar, el maíz, la palma aceitera, etc. (Webb \& Coates, 2012). Este cambio del uso de la tierra cultivable provocó escasez de recursos agrícolas y aumentó los precios de los cultivos de alimentos. En décadas recientes, múltiples estudios científicos vienen utilizando materias primas alternativas para mejorar las tecnologías de producción de biocombustibles y proponer soluciones sostenibles a los problemas mundiales de energía, al impacto medioambiental y altos precios del petróleo, (Webb, 2016; Enamala et al., 2018; Das \& Varanasi, 2019).

Según la British Petroleum (2020), Estados Unidos y Brasil producen el $52,6 \%$ y $31,3 \%$ de bioetanol, respectivamente; Europa produce el $34,3 \%$ de biodiesel. El principal consumidor de bioetanol es Estados Unidos con 49,4\%, seguido de Brasil con 31,1\%; mientras que Europa y Asia Pacifico consumen 39,9\% y 26,4\% de biodiesel.

\section{Tipos de biocombustibles}

En general, los biocombustibles por su naturaleza son sólidos (leña, carbón vegetal, astillas y pellets de madera), líquidos (bioetanol, biodiésel, etc.) y gases (biogás, gas de 
síntesis, etc.), investigados, producidos y utilizados intensamente (Guo et al., 2015). Para obtener energía y calefacción pueden ser usados directamente (biocombustibles primarios) o transformarse (biocombustibles secundarios) considerando la evolución sistemática de cuatro generaciones de biocombustibles, en función del tipo de recurso renovable y mediante tres rutas de conversión tecnológica: fisicoquímica (biomasa en combustibles líquidos), bioquímica (fermentación), termoquímica (combustión, gasificación y pirólisis) (Dutta et al., 2014; Dalena et al., 2019). La Figura 1 muestra una clasificación de los biocombustibles.

\subsection{Primera generación de biocombustibles}

Los biocombustibles de primera generación es la forma más convencional de producción, siendo el bioetanol y el biodiesel los únicos biocombustibles comercializados con éxito hasta ahora (Guo et al., 2015; Dalena et al., 2019). Obtenidos de cultivos agrícolas comestibles (caña de azúcar, maíz, sorgo, palma aceitera y semillas oleaginosas), donde el consumo excesivo de estos recursos impacta negativamente en el suministro de alimentos (World Bioenergy Association, 2019; Das \& Varanasi, 2019). Estados Unidos y Brasil son los principales productores de bioetanol en el mundo, emplean el maíz y la caña de azúcar como materia prima. El Reino Unido y Australia emplean el trigo como principal materia prima para la industria del etanol (Basile \& Dalena, 2019).

\subsection{Segunda generación de biocombustibles}

Los biocombustibles de segunda generación son considerados más ecológicos que los de primera generación, son obtenidos de desechos agrícolas y forestales, residuos industriales y municipales (Enamala et al., 2018). La biomasa lignocelulósica, es un recurso renovable más abundante y disponible con producción anual mundial de 10-20 billones de toneladas secas, (Aro, 2016). Estos biocombustibles de segunda generación, líquidos o gases son producidos a nivel laboratorio; existen varias rutas tecnológicas de conversión, sin embargo, ninguna ha alcanzado totalmente su disponibilidad comercial por el aumento drástico de costos productivos (Singh K. et al. 2017; Basile \& Dalena, 2019; Luhani et al., 2020).

\subsection{Tercera generación de biocombustibles}

Los biocombustibles de tercera generación son considerados una opción plausible como fuente de energía sostenible, superan las debilidades a los de primera y segunda generación, provienen de procesar fuentes microbianas y algas, no requieren utilizar terrenos agrícolas, los estanques o reactores en los que se cultivan pueden ubicarse en tierras improductivas; (Lackner, 2015; Martins et al., 2018; Bibi et al., 2017; Enamala et al., 2018). Las microalgas son microorganismos fotosintéticos que utilizan la energía de la luz para su crecimiento, asimilan el $\mathrm{CO}_{2}$ atmosférico de manera más eficiente comparadas con las plantas terrestres, demuestran potencial para producir biocombustibles y coproductos, con mayor rendimiento y menor consumo de recursos (Aro, 2016; Khan et al., 2018; de Farias \& Bertucco, 2019; Basile \& Dalena, 2019; Morales-Sánchez et al., 2020; Harvey \& Ben-Amotz, 2020). Existen diversos estudios sobre microalgas con alta capacidad de acumular grandes cantidades de ácidos grasos en su biomasa, con una productividad 4 a 5 veces mayor de aceite comparada con las plantas terrestres más productivas, para producir biodiesel (Khan et al., 2018; Vinoth et al., 2019; Gojkovic et al., 2020; Cui et al., 2020; Gong \& Huan, 2020). Estudios recientes reportan elevados niveles acumulados de carbohidratos en biomasa microalgal, siendo la glucosa el principal azúcar y que puede alcanzar hasta el 90\% de los azúcares totales, cuando existe inducción adecuadas de las células. Este tipo de microalgas es una materia prima alternativa para obtener bioetanol y otros productos de la fermentación (Sánchez et al., 2017; da Maia et al., 2018; Agustini \& Febrian, 2019; Sánchez, 2019; Rempel et al., 2019; Bader et al., 2020; Jeong et al., 2020). A pesar de las numerosas ventajas, las tecnologías para obtener biocombustibles de tercera generación están en fase de desarrollo, por las barreras técnico-económicas en la implementación a gran escala comercial, por sus altos costos.

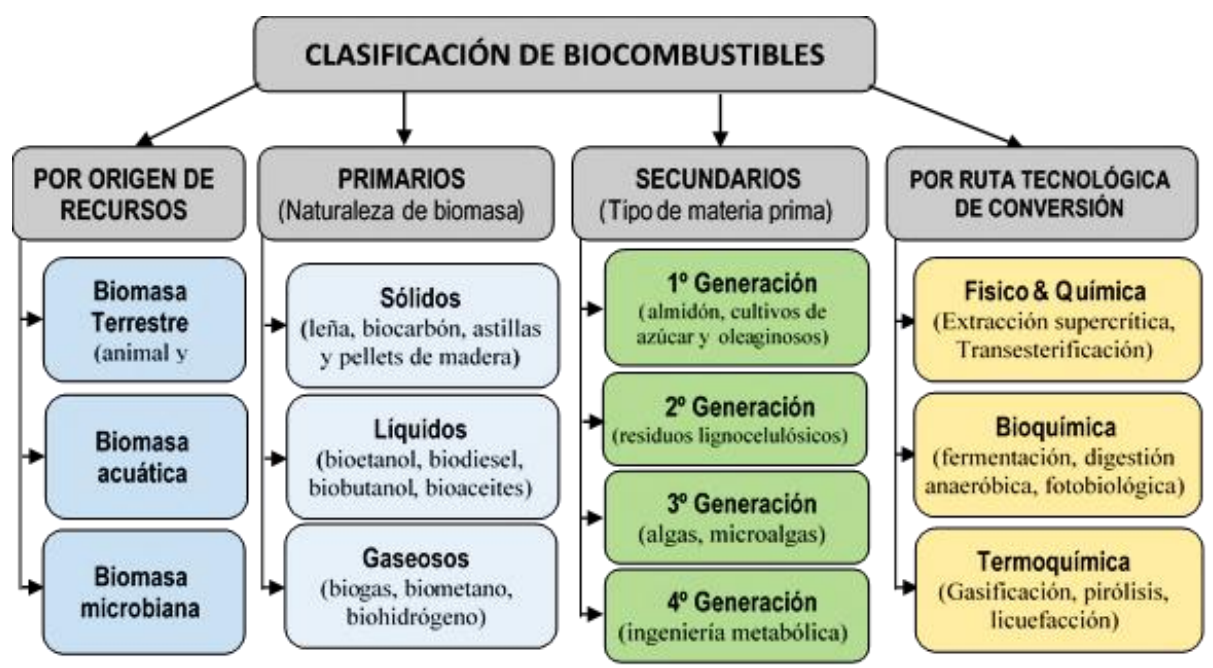

Figura 1. Esquema de la clasificación de los biocombustibles. Elaborado con información de Dutta et al. (2014), Guo et al. (2015), Dalena et al. (2019), Fan et al. (2020). 


\subsection{Cuarta generación de biocombustibles}

Los biocombustibles de cuarta generación utilizan algas genéticamente modificadas, usando ingeniería metabólica, con la intención de evitar la destrucción de la biomasa con la captura y el almacenamiento completo del $\mathrm{CO}_{2}$, con proceso neutral o negativo en carbono (Aro, 2016). Pueden generarse biocombustibles solares, electrocombustibles y biocombustibles sintéticos; el tipo y calidad, de biocombustible, dependerá de la naturaleza de la biomasa microalgal genéticamente diseñadas y optimizadas. Estos biocombustibles serán muy útiles en un determinado país, limitados por la biomasa disponible y la tecnología, que restringe su aplicación a escala global (Aro, 2016; Moravvej et al., 2019; Mat Aron et al., 2020).

a) Los biocombustibles solares. Se logra adaptando microorganismos fotosintéticos vivos como células de diseño, y mediante herramientas de biología sintética convertir eficientemente la energía solar en combustible, usando solo $\mathrm{CO}_{2}$ y agua como sustratos inagotables, baratos y ampliamente disponibles (Aro, 2016). Requiere comprensión rigurosa del mecanismo recolector de luz natural, de las enzimas asociadas y los medios metabólicos del carbono de los organismos fotosintéticos. Se han realizado demostraciones exitosas con cianobacterias, introduciendo en su genoma varias rutas metabólicas fermentativas para obtener productos químicos valiosos y biocombustibles como hidrógeno, etanol, butanol y ácido láctico (Aro, 2016; Moravvej et al., 2019).

b) Los electrocombustibles. Se obtienen combinando las células fotovoltaicas o células solares y los sistemas bioelectroquímicos. Productos químicos y combustibles reducidos, pueden generarse mediante electrosíntesis microbiana, utilizando $\mathrm{CO}_{2}$ y electrones de electrodos sólidos como fuentes de carbono y energía, respectivamente (Patil et al. 2015; Aro, 2016). Esta tecnología se encuentra en etapa inicial de investigación, se realizaron unos pocos estudios de prueba con resultados prometedores para producir y almacenar eficientemente biocombustibles líquidos. La clave del proceso, y el eslabón débil de esta tecnología, es la captura y el secuestro de $\mathrm{CO}_{2}$, (Aro, 2016; Mat Aron et al., 2020).

c) Los biocombustibles sintéticos. Este campo todavía está en su fase inicial y solo unos pocos ejemplos, a nivel de laboratorio, verdaderamente sintéticos han sido publicados hasta ahora. Comprende el diseño y la construcción de nuevas partes (de dispositivos y sistemas biológicos), control del crecimiento de las células sintéticas que inhalarán $\mathrm{CO}_{2}$ y excretarán azúcares, desarrollar rutas metabólicas para obtener productos químicos de interés y generar biocombustibles rentables (Aro, 2016; Moravvej et al., 2019).

Aunque el biocombustible de cuarta generación es una buena alternativa energética, los posibles riesgos ambientales y relacionados con la salud es un motivo de gran preocupación, porque no existen suficiente cantidad de pruebas aparentes que respalden una posible transferencia genética horizontal y de la productividad de las cepas (Abdullah et al., 2019).

\section{Las microalgas}

\subsection{Descripción general e importancia}

Las algas son especies vegetales unicelulares o pluricelulares, constituido por macroalgas, microalgas y cianobacterias; viven preferentemente en el agua, tanto dulce como marina, generalmente provistas de clorofila, acompañada en ocasiones de otros pigmentos de colores variados que la enmascaran (Barsanti \& Gualtieri, 2014). Las microalgas es un grupo muy diversificado de microorganismos unicelulares, con tamaño de celda 2200 um (Velazquez-Lucio et al., 2018), al estar sumergidas en un ambiente acuoso poseen una elevada relación superficie-volumen, factor que permite absorber la mayor cantidad de $\mathrm{CO}_{2}$ y nutrientes presentes, y mediante fotosíntesis convertir la energía solar en gran cantidad de biomasa microalgal que puede contener lípidos, proteínas o carbohidratos, demostrando ser recurso energético para obtener biocombustibles (Chowdhury et al., 2019; Bux \& Chisti, 2016)

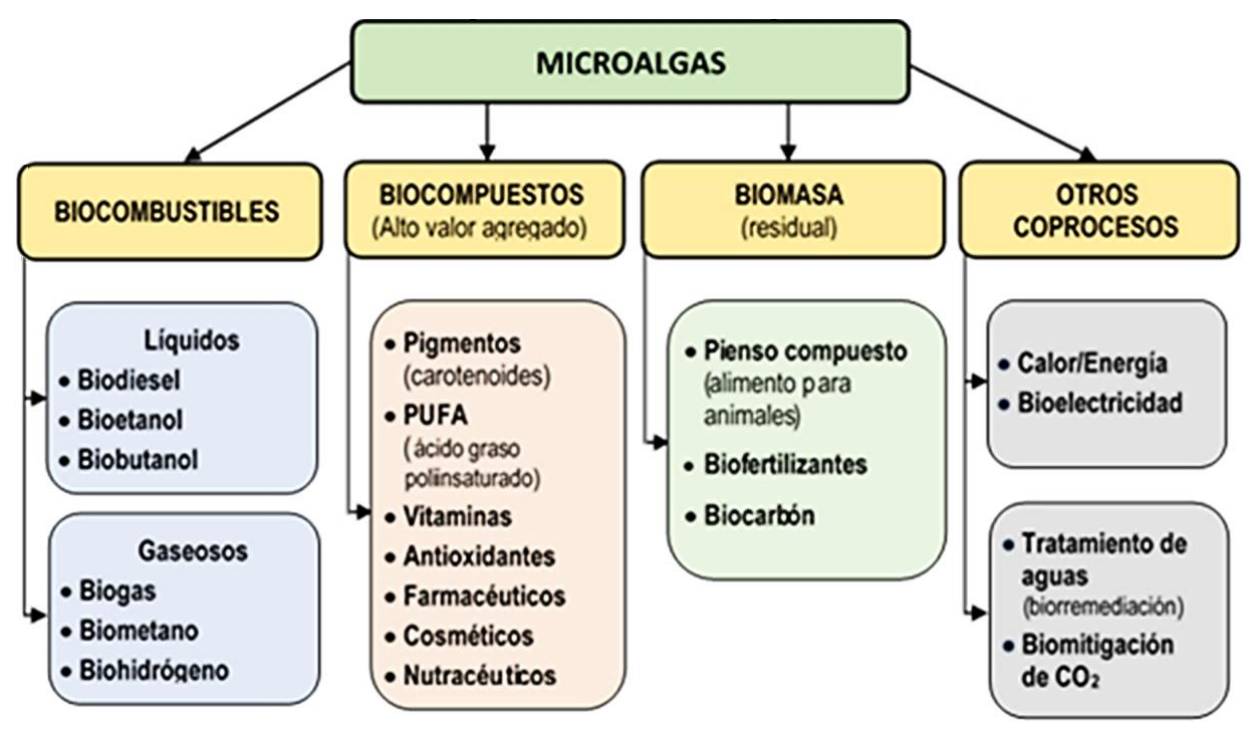

Figura 2. Aplicaciones potenciales de las microalgas. 
Tabla 1

Características de algunos grupos relevantes de microalgas

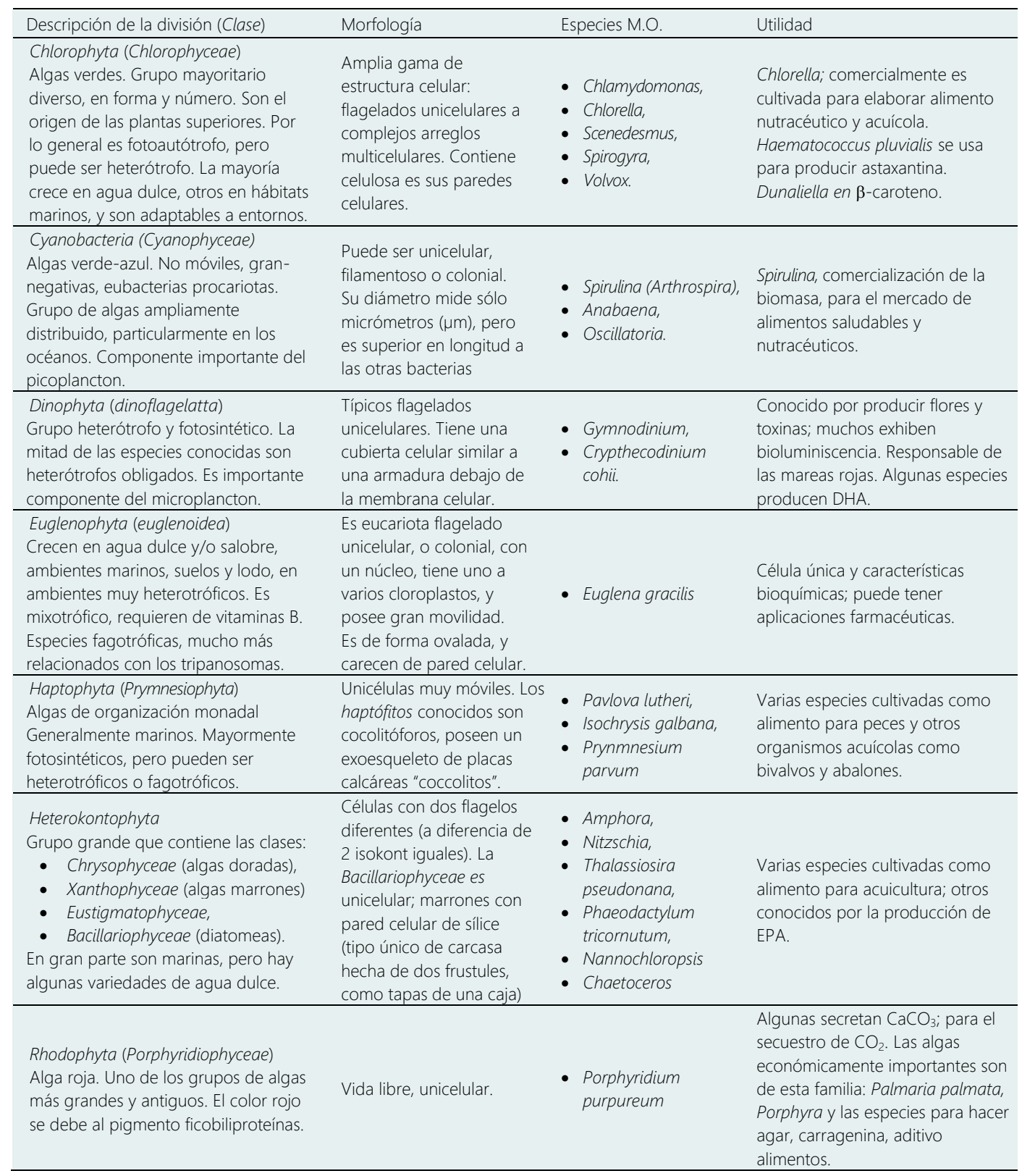

Nota: con información de Baltz et al., (2010); Barsanti y Gualtieri, (2014), y Algaebase (2020)

La investigación sobre las diversas aplicaciones de las microalgas ha ganado interés durante los últimos años, por su amplia ventaja sobre los cultivos terrestres como fuente de biomasa y potencial energético; los aspectos más importantes a considerar son las siguientes: (a) Las microalgas poseen sistemas biológicos efectivos para convertir energía solar en compuestos orgánicos, no poseen un sistema reproductor complejo sino un ciclo simple de presión celular (Singh et al., 2017); (b) crecen en ambientes de agua dulce o salobre, en tierras no cultivables. No compiten con la seguridad alimentaria. No requieren herbicidas ni pesticidas para su cultivo (Enamala et al., 2018); (c) presentan ciclos de cosecha muy cortos (110 días) comparados con los cultivos convencionales (una o dos veces al año), pueden duplicar su biomasa en períodos desde 3,5 h y hasta 24 h, la producción de biomasa al absorber y fijar $\mathrm{CO}_{2}$, ayuda a reducir los niveles del gas de efecto invernadero $(1,8 \mathrm{~kg} \mathrm{CO} / \mathrm{kg}$ biomasa seca) en la atmósfera (Chisti, 2007); (d) existen técnicas de cultivo para manipular diversas especies de microalgas e inducirlas a acumular grandes cantidades de biomasa donde sus componentes comunes son lípidos, pigmentos, ácidos nucleicos, cenizas y otros compuestos, pudiendo alcanzar concentraciones extremadamente altas (Alam et al., 2015; Singh et al., 2017); varios estudios de investigación reportan alta productividad del aceite de microalgas, que supera a los cultivos oleaginosos, para obtener biodiesel (Vinoth et al., 2019), este tipo de 
biomasa microalgal contiene rangos de aceite de 20-50\% en peso seco de biomasa (Dass \& Varanasi, 2019); (e) también existen algunas especies de microalgas inducibles para que acumulen la mayor cantidad de carbohidratos, sustrato principal para producir bioetanol (Dalena et al., 2019; Bader et al., 2020), en la biomasa microalgal generada es nula la presencia de lignina, ventaja que facilita un proceso de pretratamiento, es decir, eficiente hidrólisis enzimática del contenido de almidón, permitiendo alcanzar altas tasas de crecimiento y gran rendimiento (Bernaerts et al., 2018a-b); ( $f$ ) algunas especies de microalgas, en condiciones anaeróbicas, producen glucógeno para generar biohidrógeno, y su fermentación produce metano; al producir más de un biocombustible el valor de la biomasa microalgal aumenta (Rempel et al., 2019; Kendir Çakmak \& Ugurlu, 2020). Por tanto; la biomasa microalgal es considerada una materia prima importante, en el concepto de biorrefinería, para obtener biocombustibles y una amplia gama de coproductos de alto valor agregado (Figura 2). Solo algunos pocos productos son obtenidos a escala industrial.

\subsection{Clasificación de las microalgas}

Son protistas fotosintéticos, organizados por similitud genética, por reino, división y clases (Tabla 1).

La clasificación en divisiones se basa en varias propiedades: pigmentación, naturaleza química del producto fotosintético, composición de la pared celular, y otras características morfológicas. Las procariotas (algas verde-azul son denominados cianobacterias, tienen dos divisiones) y eucariotas (diatomeas, algas verdes, algas rojas y doradas, con amplia morfología y filogenia, poseen nueve divisiones), crecen rápidamente y pueden vivir en condiciones desfavorables, por su estructura celular simple y bajo requerimiento nutricional (Baltz et al., 2010; Barsanti \& Gualtieri, 2014). El número total de especies de algas es incierto, estimaciones del número de algas vivas varía de 30.000 a más de 1 millón de especies (Barsanti \& Gualtieri, 2014). Actualmente puede disponerse de datos taxonómicos confiables, recientemente están documentados 160.881 especies de algas descritas con nombres infraespecíficos, 22.718 imágenes, 62.568 elementos bibliográficos y 473.190 registros de distribución, en la base de datos de AlgaeBase (2020).

\subsection{El metabolismo de las microalgas}

En todos los organismos fotosintéticos ocurre el mismo proceso de reacción metabólica, el factor más importante es la absorción de nutrientes del entorno a través de diversos procesos bioquímicos y de transporte. En las rutas metabólicas fotosintéticas, el carbono (C) y nitrógeno ( $\mathrm{N}$ ) son los más importantes elementos. Los principales cambios que ocurren durante las rutas metabólicas son la masa y volumen de las células, densidades, las proteínas, la clorofila, el ARN y el contenido de vitaminas (Kim, 2015; Enamala et al., 2018).

a) Metabolismo del carbono. Inicia incorporando glucosa en las células de las algas y produce Glu-6-P (glucosa-6fosfato) al adicionar el grupo fosfato a la hexosa, fácilmente accesible para el almacenamiento, crecimiento y respiración celular. En las condiciones más oscuras, las algas no pueden metabolizar la glucosa porque se expulsa un pequeño suministro de energía a través de la disimilación de glucosa (Goncalves et al., 2016). La cantidad insuficiente de la enzima lactato deshidrogenasa ralentiza el proceso, la mayor parte de la glucosa se convierte en oligosacáridos y polisacáridos (Enamala et al., 2018).

Tabla 2

Descripción taxonómica y morfológica de la microalga Porphyridium cruentum

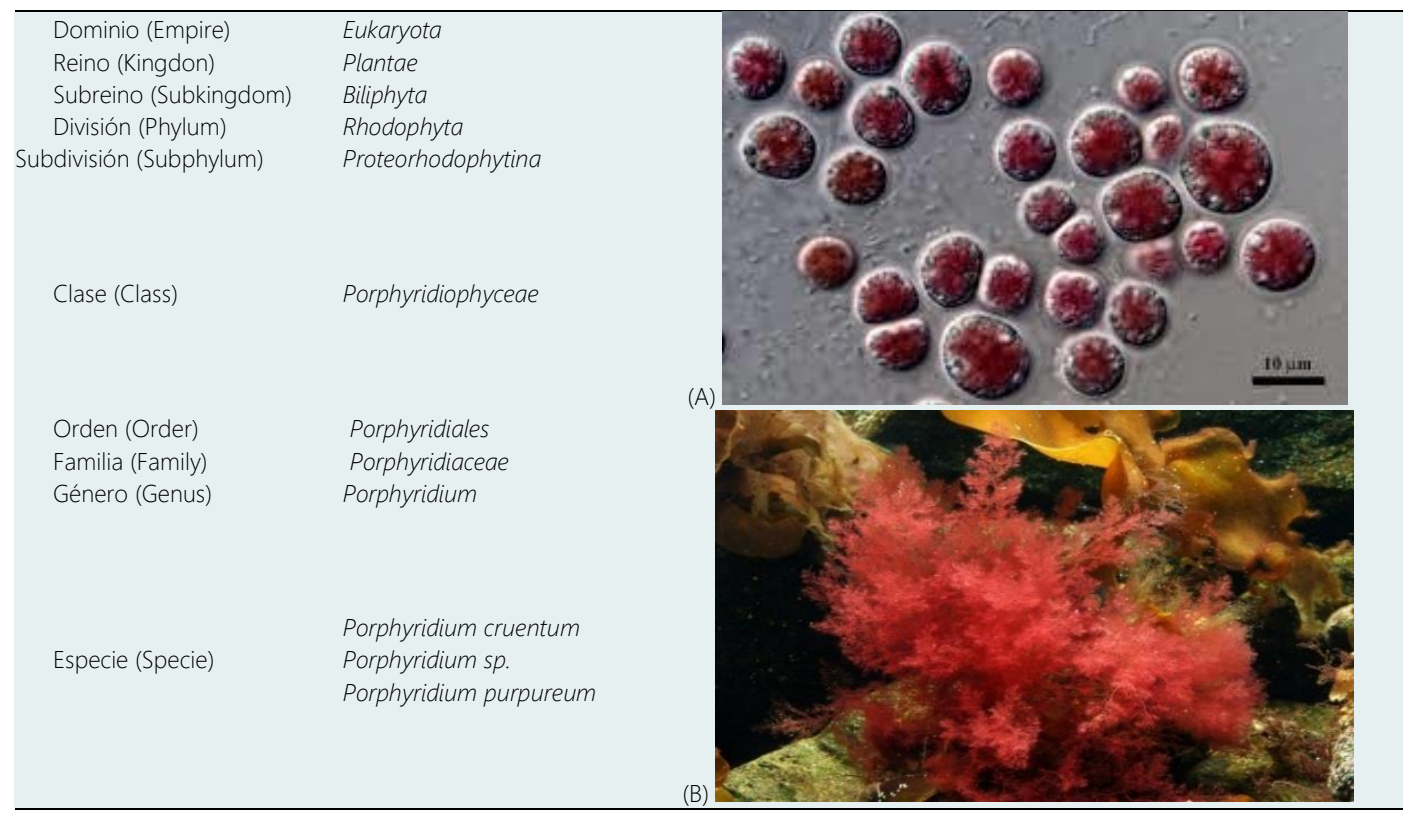

Nota: datos de registro taxonómico tomado de https://www.algaebase.org/search/species/detail/?species_id=14589

Micrografías corresponden a algas rojas marinas Porphyridium cruentum, describe: (A) las células vistas en microscopio

(https://algaeresearchsupply.com/products/copy-of-algae-culture-porphyridium-cruentum) y (B) algas en su hábitat natural (https://www.5lepestkov.com/wpcontent/uploads/2015/09/1109a-68.jpg) 
b) Metabolismo del Nitrógeno. Existe interconexión metabólica del $\mathrm{C}$ y el $\mathrm{N}$ en las microalgas. Las fuentes de nitrógeno son catalizadas por la enzima glutamina sintasa, que tiene una gran afinidad con el amoníaco y puede incorporarlo fácilmente en las células (Goncalves et al., 2016). El amonio $\left(\mathrm{NH}_{4}{ }^{+}\right)$, disponible libremente, es combinado con la forma inorgánica para formar aminoácidos, requieren un esqueleto $C$ y pueda generar cetoácidos, liberando energía en forma de moléculas de ATP, necesario para sintetizar aminoácidos: glutamato, aspartato y glutamina (Enamala et al., 2018).

c) Metabolismo de la úrea. En la fisiología y ecología de las diversas especies de algas la urea tiene un papel muy importante, generalmente está presente en el ambiente acuático con concentraciones por debajo de $1 \mu \mathrm{M}-\mathrm{N}$, y contribuye con el $50 \%$ o más del $\mathrm{N}$ total utilizado por las algas. Urea sintetizada comercialmente y la formada naturalmente como subproducto del metabolismo celular, son fuentes importantes de N (Kim, 2015; Hong \& Lee, 2015). Existen diversas vías metabólicas para regular la absorción de urea, con diferentes fuentes de energía y cinéticas enzimáticas. Antes de asimilarse, en muchas bacterias y eucariotas, la urea puede utilizar las enzimas ureasa y amidoliasa (UALase) y descomponerse en $\mathrm{NH}_{4}{ }^{+}$ y $\mathrm{CO}_{2}$, (Enamala et al., 2018).

\subsection{Morfología y taxonomía de la microalga} Porphyridium cruentum

La microalga roja Porphyridium cruentum es una eucariota, unicelular, que pertenece a la división Rhodophyta y clase Porphyridiophyceae. Crece en ambiente marino salobre, en aguas poco profundas, y algunas veces en agua dulce (Algaebase, 2020); las células son esféricas con 6-16 $\mu \mathrm{m}$ de diámetro, encapsuladas por una pared celular en un complejo de polisacáridos sulfatados (Bernaerts et al., 2018a-b). El color rojo característico es por los pigmentos (carotenoides) ficoeritrina y ficocianina. Además, los carotenoides y la clorofila-a tienen la función de ser una especie de antena para atrapar a los fotones necesarios y realizar la fotosíntesis (Kim et al., 2017; Agustini \& Febrian, 2019) (Tabla 2).

Estudios de caracterización, bioquímica y biológica, de la microalga Porphyridium cruentum, reportan que la energía absorbida por fotosíntesis es almacenada como proteínas (28-39\%), carbohidratos 40-57\%), y lípidos (9$14 \%)$. Por tanto, es una potencial fuente natural para producir biocombustibles y una variedad de compuestos bioactivos interesantes (Tiwari et al., 2019; Li et al., 2019). La concentración de estos compuestos bioquímicos depende de las condiciones del medio de cultivo y las de crecimiento de las microalgas (Lutzu et al., 2017; Bernaerts et al., 2018a-b; Velazquez-Lucio et al., 2018). Los lípidos y carbohidratos (xilosa, glucosa, galactosa) se encuentran intracelularmente, por su contenido de exopolisacáridos en la pared celular, constituida principalmente por celulosa y casi nula cantidad de lignina. Además, de biocombustibles, puede obtenerse productos farmacéuticos, de acuicultura, biomedicina, nutricionales. El pigmento ficoeritrina posee propiedades de tinte natural, es usado en alimentos y en la industria cosmética (Kim et al., 2015; Bernaerts et al., 2018a-b; Gallego et al.,
2019; Li et al., 2019; de Farias \& Bertucco, 2019), Por tanto; para valorizar la biomasa microalgal, debe desarrollarse procesos biotecnológicos viables.

\section{Factores influyentes en el cultivo y crecimiento de las microalgas}

Las microalgas son cultivadas en modos autotrófico (inorgánicos), heterotrófico (orgánicos) y mixotrófico (combinación de autotróficos y heterotróficos), en estanques de canalizaciones exteriores o fotobiorreactores interiores. Combinar los diferentes modos de cultivo generaría altos rendimientos de biomasa (Lackner, 2015; Kahn et al., 2018; Tiwari et al., 2019).

5.1. Microalgas autotróficas. Emplean $\mathrm{CO}_{2}$ como fuente de carbono y luz solar como fuente de energía para acumular aceite bajo condiciones especiales. Estas microalgas autotróficas (Scenedesmus Acutus, Chlorella vulgaris, Botryococcus braunii, Navicula pelliculosa, Crypthecodinium cohnii, Dunaliella primolecta, Monallanthus salina, Neochloris oleoabundans, Phaeodactylum tricornutum y Tetraselmis sueica), pueden acumular aceites (Chisti, 2007; Lackner, 2015; Mathimani et al., 2015; Martins, 2018).

5.2. Microalgas heterotróficas. Para su metabolismo obtienen energía desde otras fuentes de carbono orgánico (como la glucosa) en lugar del $\mathrm{CO}_{2}$ y la luz solar. Este tipo de microalgas cultivadas y controladas en fermentadores normales puedan acumular, hasta cierto límite, lípidos y carbohidratos de alta calidad (Singh et al., 2017; Velazquez-Lucio et al., 2018). Al cambiar las condiciones de cultivo, o usando ingeniería genética, algunas microalgas autotróficas podrían convertirse en heterotróficas, pueden crecer mixotróficamente, (Lackner, 2015; Enamala et al., 2018; Velazquez-Lucio et al., 2018). Un cultivo y crecimiento exitoso de microalgas, en capacidad productiva de biomasa con buena acumulación de carbohidratos y lípidos, requiere adecuadas condiciones ambientales. Los medios influyentes son: factores abióticos (intensidad de la luz, temperatura, $\mathrm{O}_{2}, \mathrm{CO}_{2}$, $\mathrm{pH}$, salinidad, nutrientes y toxinas), factores bióticos (bacterias, hongos, virus y competencia con otras microalgas por nutrientes), y factores operativos (grado de mezcla y agitación, ancho y profundidad del tanque de cultivo, tasa de dilución, frecuencia de cosecha y la adición de bicarbonato), (Enamala et al., 2018; Medina-Cabrera et al., 2018; Tiwari et al., 2019). A continuación, una descripción concisa de los factores influyentes más relevantes:

a) Luz es la fuente básica de energía para los organismos fotoautotróficos. La intensidad de la luz y el fotoperíodo, son los factores más influyentes en la velocidad de crecimiento y la composición de la biomasa y, por tanto, en la acumulación de productos de alto valor en una amplia gama de especies de algas (Tiwari et al., 2019; Enamala et al., 2018). Las alteraciones en el fotoperíodo indujeron cambios en el contenido total de proteínas, pigmentos y ácidos grasos en Porphyridium cruentum, y la densidad celular, la tasa de crecimiento celular y contenido total de lípidos en Nannochloropsis sp., C. vulgaris, Dunaliella sp. S. obliquus y C. kessleri (Chisti, 2007). La tasa de crecimiento de los cultivos microalgales aumenta al incrementar la intensidad de la luz, hasta 
alcanzar la luz saturante (alrededor de $200-400 \mu \mathrm{E} / \mathrm{m}^{2} \mathrm{~s}$ ). La luz sobresaturada puede conducir a formar especies reactivas al oxígeno, perjudicial para las microalgas (fotoinhibición), que disminuye la productividad de la biomasa (Barsanti \& Gualtieri, 2014). Un estudio sobre Chlorella sp mostró un aumento en la densidad celular cuando la población estuvo expuesta a la luz intermitente (Kim et al., 2015; Tiwari et al., 2019).

b) Temperatura es un factor limitante clave para sistemas de cultivo de algas al aire libre. Idealmente, los cultivos deben mantenerse a una temperatura lo más cercana posible a la temperatura en que se recolectaron los microorganismos. Aunque pueden sobrevivir a una variedad de temperaturas, el crecimiento está limitado a un rango óptimo de $\left(20-30^{\circ} \mathrm{C}\right)$. Temperaturas inferiores a $16{ }^{\circ} \mathrm{C}$ ralentiza el crecimiento, mientras que las superiores a $35^{\circ} \mathrm{C}$ son letales para varias especies, con la pérdida total del cultivo (Barsanti \& Gualtieri, 2014; Kim et al., 2015). Cambios climáticos puede generar sobrecalentamiento en cultivos exteriores, debe considerarse un sistema de refrigeración por agua para garantizar que la temperatura no exceda el rango óptimo (Chisti, 2007). Puede lograrse alta producción de biomasa microalgal, aumentando la temperatura hasta llegar al óptimo en las mañanas y disminuir por las noches para evitar pérdida de biomasa. Temperaturas bajas, causada por la respiración en períodos oscuros, reducen pérdida de biomasa (Kim et al., 2015; Tiwari et al., 2019; Carneiro et al., 2020).

c) Nutrientes el suministro de nutrientes a cultivos de microalgas deben incluir elementos inorgánicos, macronutrientes, vitaminas y oligoelementos. Los macronutrientes más requeridos son nitrógeno y fósforo (16 N: 1P) y silicio. La deficiencia o limitación de N/P durante el cultivo microalgal puede mejorar la acumulación de lípidos, para evitar la limitación se agregan diferentes tipos en relaciones excesivas, incluso cuando se cultiva la misma alga (Kim et al., 2015). En la práctica, en las primeras etapas las especies de microalgas son cultivadas en medios con suficientes nutrientes, y durante las etapas posteriores la limitación de nutrientes debe diseñarse para mejorar el contenido de lípidos y/o carbohidratos. La deficiencia de nitrógeno podría causar disminución de aminoácidos, mientras que las cantidades de lípidos neutros aumentan enormemente (Kim et al, 2015; Enamala et al., 2018; Tiwari et al., 2019).

d) Dióxido de carbono es necesario un suministro suficiente de $\mathrm{CO}_{2}$, factor de eficiencia positiva de la fotosíntesis, para el crecimiento de las microalgas e induce la síntesis de proteínas relevantes, y es uno de los factores clave que influyen en la acumulación de carbohidratos en la biomasa microalgal (Kim et al., 2015; Enamala et al., 2018). Algunas especies de algas, heterótrofas y mixotróficas, utilizan carbono puro (glucosa) para su crecimiento; el principal beneficio es reducir la dependencia del suministro de luz, permitiéndoles su crecimiento en la oscuridad (Kim et al., 2015). Sin embargo, bajo condiciones de escasez de nitrógeno, con un suministro adecuado de $\mathrm{CO}_{2}$ y energía luminosa, el contenido de proteínas puede ser consumido como fuente de nitrógeno, y la cantidad de carbohidratos puede aumentar significativamente (Chen et al., 2013). e) $\mathrm{pH}$ es un factor muy importante en el crecimiento de algas, porque determina la solubilidad y disponibilidad de $\mathrm{CO}_{2}$ y nutrientes esenciales. El rango de $\mathrm{pH}$ para la mayoría de las especies de algas cultivadas está entre 7 y 9, con rango óptimo 8.2 y 8.7, aunque hay especies que habitan en ambientes más ácidos/básicos (Barsanti \& Gualtieri, 2014). En cultivos alcalinos, las microalgas capturarán fácilmente el $\mathrm{CO}_{2}$ atmosférico y aumenta la flexibilidad de su pared celular, evitando su ruptura y acumulando más biomasa como triglicéridos, (Enamala et al., 2018; Kim et al., 2015). Un valor de $\mathrm{pH}$ ácido $(\mathrm{pH}<5)$, indica que $\mathrm{CO}_{2}$ es el carbono inorgánico disuelto (DIC). El $\mathrm{pH}$ aumenta gradualmente a básico a medida que crece la biomasa microalgal y genera un aumento instantáneo de la fotosíntesis y la agregación de iones $\mathrm{OH}^{-}$(Enamala et al., 2018). Un pH más alto del rango óptimo limita la disponibilidad de $\mathrm{CO}_{2}$, suprimiendo el crecimiento de algas. El colapso completo de un cultivo microalgal, por interrupción de varios procesos celulares, puede ser el resultado de no mantener un $\mathrm{pH}$ aceptable (Barsanti \& Gualtieri, 2014).

f) Salinidad es uno de los factores ecológicos más importantes que afectan el crecimiento y las actividades metabólicas de las plantas y microorganismos, alterando su composición bioquímica. Las algas pueden producir algunos metabolitos para autoajustar la matriz de salinidad y protegerse, al equilibrar la influencia del estrés osmótico del entorno. Una alta salinidad induciría la saturación de ácidos grasos y aumenta la productividad del biodiesel (Chen et al., 2013). Las microalgas marinas son muy tolerantes a las condiciones de mayor salinidad en comparación con las de agua dulce, la mayoría de las especies crecen mejor con salinidad ligeramente más baja que la de su hábitat nativo (Enamala et al., 2018). Se ha encontrado salinidades optimas de 20 a $24 \mathrm{~g} / \mathrm{L}$. Una salinidad del 35\% (agua de mar estándar) o superior conduce a una reducción en la tasa de crecimiento y de la eficiencia fotosintética y la respiración oscura (Barsanti \& Gualtieri, 2014).

g) Mezcla; el cultivo de microalgas debe mezclarse y agitarse para, evitar la sedimentación de las células que al apilarse impiden su crecimiento, tener la biomasa en suspensión e igualmente espaciada y expuesta uniformemente a la luz, prevenir efectos de limitación de nutrientes y metabolitos, evitar la estratificación térmica (p.ej., en cultivos al aire libre), intercambio eficiente de gases entre el medio de cultivo y el aire que contiene la fuente de carbono $\left(0.03 \%\right.$ de $\left.\mathrm{CO}_{2}\right)$ para la fotosíntesis (Barsanti \& Gualtieri, 2014; Kim et al., 2015). Existen varios tipos de mezcla, como agitación mecánica, aireación con bombas de aire, ruedas de paletas y bombas de chorro, etc., se utilizan según el tipo y la escala del sistema de cultivo. Una mezcla rápida también se asocia con daño celular físico, que depende del tipo de alga, su tamaño y tipo de pared celular (Singh et al., 2017).

\section{Técnicas para el cultivo de microalgas}

Un cultivo es un entorno artificial en el que crecen las algas, existe una amplia variedad de sistemas para cultivarlas. Es muy importante elegir el entorno artificial para una población de células, con hábitat de condiciones comple- 
jas y fluctuantes, porque inevitablemente provocan un período de adaptación, donde el crecimiento poblacional no se producirá o será muy lento. En teoría, en lo posible, las condiciones de cultivo deberían parecerse al entorno natural del alga (Bibi et al., 2017; Kim et al., 2017; Martins et al., 2018). El medio de cultivo debe prepararse e introducirse en los sistemas de producción donde se produce la biomasa, luego debe cosecharse y estabilizarse (Figura 3). Las principales técnicas son:

a) Cultivo en sistema abiertos. Son los sistemas más comunes, fácil de construir y operar, económicos, usados para el cultivo en masa de algas y cianobacterias. Los medios pueden ser naturales (lagunas y estanques) o artificiales (estanques longitudinales o circulares, construidos en varios diseños) solo pueden albergan un número limitado de especies que puedan tolerar condiciones ambientales extremas, y son comparativamente inadecuados para cultivar la mayoría de las especies de algas (Bibi et al., 2017; Martins et al., 2018). Estas especies de microalgas: Chlorella, Spirulina y Dunaliella, se adaptan rápidamente a estos sistemas con ambientes altamente alcalinos o salinos (Chisti, 2007). La tecnología actual ofrece cuatro tipos principales: (i) estanques abiertos sin mezclar, (ii) estanques de canalización, (iii) estanques circulares, y (iv) estanques inclinados, de capa delgada, sin mezclar (Kim et al., 2015). Los estanques abiertos sin mezclar tienen baja productividad $\left(<1,0 \mathrm{~g} \mathrm{~m}^{-2} \mathrm{~d}^{-1}\right)$, los de canalización son los más utilizados para el cultivo comercial de Spirulina, Haematococcus y Dunaliella (Chisti, 2007).

b) Fotobiorreactores son sistemas cerrados que ofrecen mejor control sobre la contaminación, transferencia de masa y otras condiciones conexas; desarrollados para superar ineficiencia y problemas de sistemas abiertos (necesitan gran área de tierra, contaminación, ambientes no controlados, evaporación, idoneidad limitada de especies, baja productividad volumétrica). Un sistema integrado, fotobiorreactor cerrado y estanque abierto, combina los beneficios individuales demostrando efectividad. Los fotobiorreactores pueden ubicarse en interiores o exteriores, dependiendo del sistema de recolección, distribución de luz y la viabilidad comercial. Existen diseños patentados diversos, p.ej: fotobiorreactores tubulares, helicoidales y de placa plana, columna de burbuja combinada y reactor tubular inclinado, columna de burbujas vertical y reactor de transporte aéreo (Singh K. et al., 2017; Bibi et al., 2017; Kim et al., 2017; Martins et al., 2018). c) Fermentadores son utilizados en cultivos heterotrófico de algas que requieren suministro suficiente de oxígeno para el catabolismo de los sustratos orgánicos consumidos como únicas fuentes de carbono y energía; incluyendo, condiciones de fermentación, alto grado de control de procesos, eliminación de luz, independencia del clima, y menores costos de cosecha (Singh K. et al., 2017). Este sistema heterotrófico aumenta el contenido total de lípidos en las algas comparado con las cultivadas fototróficamente, p.ej., la Chlorella acumula lípidos un aproximado de $55 \%$ frente al $14,6 \%$, en peso seco; usualmente (pero no siempre), un cultivo heterotrófico posee mayores rendimientos (Kim et al., 2015).

\section{Técnicas para la cosecha de biomasa microalgal}

La cosecha (o recolección) implica una secuencia de procesos para eliminar agua contenida en un cultivo de biomasa microalgal. La naturaleza extremadamente diluida de los cultivos y el pequeño tamaño de las células algales hace que la cosecha de la biomasa microalgal sea intensiva en energía y costos operacionales (Bux \& Chisti, 2016; Mathimani \& Mallic, 2018; Najjar \& Abu-Shamleh, 2020). Las características del cultivo (p.ej.: tamaño y densidad, el valor agregado del producto final) influyen para seleccionar una técnica de recolección. Para conservar la energía y reducir costos, las algas son recolectadas en un proceso de dos etapas: (1) cosecha a granel para separar la biomasa de la suspensión, puede alcanzar valores del 2 al 7 \% de materia sólida total, de la concentración inicial del cultivo, y las operaciones utilizadas son: floculación, flotación o sedimentación; (2) espesamiento para concentrar la lechada a través técnicas más intensas (centrifugación, filtración y ultrasonido), es una etapa más intensiva en energía que la cosecha a granel; (Enamala et al., 2018; Mathimani \& Mallic, 2018; Najjar \& Abu-Shamleh, 2020). Existen otras técnicas (electroforesis, electroflotación y ultrasonido) consideradas de menor importancia (Enamala et al., 2018), y nuevas técnicas de vanguardia (biofloculación por microalgas, floculación por ajuste de pH y recolección basada en nanocompuestos magnéticos). Por tanto, obtener biomasa desde los caldos de cultivo diluidos de microalgas requiere separar grandes volúmenes de agua, a un significativo costo de recolección, que es un factor económico muy crucial que dificulta la comercialización de productos (Mathimani \& Mallic, 2018). A continuación, se describen los procesos convencionales más usados: floculación, centrifugación y filtración.
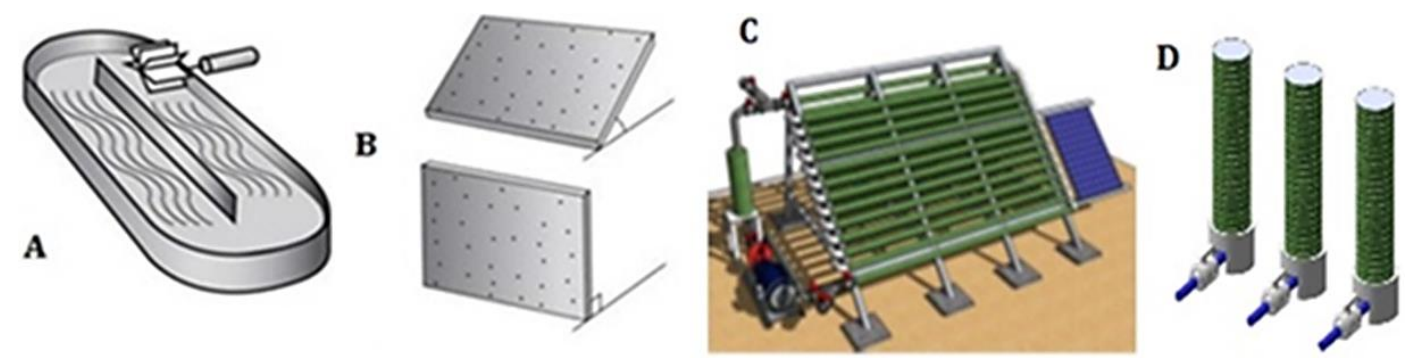

Figura 3. Esquemas de sistemas de cultivo para microalgas. Sistema abierto (A), tipo carrusel HRAP; sistema cerrado (B), fotobiorreactor en paneles; fotobiorreactores tubulares (C y D). Ref.: Figuras (A y B) tomados de Hernández-Pérez y Labbé (2014); y las Figuras (C y D) de http://proyectotres.itccanarias.org/files/3-David_Rodriguez-Diseo_fotobiorreactores.pdf 
a) Floculación es un método que aglutina a las unidades coloidales dispersas para formar flóculos, facilitando su decantación y posterior filtrado. Puede ocurrir espontáneamente porque las células de algas producen un agente floculante, o es inducida por floculación química, biofloculación, electrofloculación y flotación con aire (Bux \& Chisti, 2016). En la floculación química, algunas partículas excedentes de floculantes inorgánicos $\left(\mathrm{FeCl}_{3}\right.$, $\left.\mathrm{Fe}_{2}\left(\mathrm{SO}_{4}\right)_{3}, \mathrm{Ca}(\mathrm{OH})_{2}, \mathrm{AlCl}_{3}, \mathrm{y} \mathrm{Al}_{2}\left(\mathrm{SO}_{4}\right)_{3}\right)$ pueden permanecer en la biomasa e interferir en la recolección y posterior extracción de lípidos. Los biofloculantes (quitosano y almidon catiónico) agregados en pequeñas cantidades producen flóculos más estables, siendo una opción más segura y atractiva (Enamala et al., 2018; Mathimani \& Mallic, 2018).

b) Centrifugación es un proceso bien establecido, utiliza la fuerza centrípeta para lograr una separación bifásica, es un método de cosecha secundaria para concentrar una biomasa microalgal desde (10 a $20 \mathrm{~g} / \mathrm{L}$ ) hasta una pasta de (100 a $200 \mathrm{~g} / \mathrm{L})$ y que podría usarse en combinación con la extracción de aceite (Kim et al., 2015). Existen factores cruciales (morfología, tamaño de partícula y densidad) que afectarían la recuperación de biomasa (y costos del proceso). Las grandes células coloniales y las filamentosas, tienden a asentarse más fácilmente que las células pequeñas individuales (Enamala et al., 2018). La centrifugación consume energía con estimaciones que oscilan entre 0,3 y $8 \mathrm{~kW}-\mathrm{h} / \mathrm{m}^{3}$; es muy costoso para producción a escala comercial; el uso se limita por una segunda etapa de filtración durante la obtención de biocombustibles de microalgas (Mathimani \& Mallic, 2018; Enamala et al., 2018; Najjar \& Abu-Shamleh, 2020).

c) Filtración es una técnica operacional para separar sistemas bifásicos solido-fluido, usando un medio filtrante con un tamaño de poro micro, a través del cual solo puede pasar el fluido y las partículas quedan retenidas. Es muy usado a nivel de laboratorio, pero su aplicación a gran escala tiene problemas: como obstrucción de la membrana, la formación de torta de filtración comprimible y mantenimiento costoso (Kim et al., 2015; Najjar \& Abu-Shamleh, 2020). Esta técnica no es apropiada para microalgas como Chlorella, Dunaliella, Scenedesmus, etc., sino que debe utilizarse para algas de gran tamaño como las especies filamentosas. Existe otra técnica, como la microfiltración, posee un tamaño de malla 15-64 $\mu \mathrm{m}$, que permite partículas muy finas, retiene la estructura, la motilidad y las propiedades de las microalgas recolectadas (Singh et al., 2017; Enamala et al., 2018).

\section{Técnicas para el pretratamiento de biomasa microalgal}

Las microalgas son organismos fotosintéticos que pueden sintetizar biomasa para ser fuente potencial de bioenergía y bioproductos; siendo la hidrólisis de su pared celular el principal problema en el proceso productivo, por lo que, debe optimizarse mediante un método de costobeneficio con balance energético positivo para la hidrólisis (Barati et al., 2021). La etapa del pretratamiento de la biomasa microalgal es relevante, para extraer los componentes intracelulares que contiene, tales como: lípidos, carbohidratos, proteínas y coproductos de valor agregado (carotenoides, oligosacáridos, antioxidantes, pigmentos, etc.), (Velazquez-Lucio et al., 2018). En la Figura 4 se describen los pretratamientos de biomasa microalgal más relevantes.

a) Métodos mecánicos son operaciones convencionales (homogenización por alta presión, cavitación hidrodinámica y molino de bolas) que ofrecen a gran escala resultados favorables con alta recuperación de los productos seleccionados. La homogenización por alta presión se basa en un principio simple, las células colocadas en suspensión son desplazadas y dirigidas por una bomba hacia un orificio con válvulas especialmente diseñadas para resistir la presión, el caudal aumenta rápidamente y la presión del fluido disminuye en una corta distancia a medida que sale del sistema, generando considerable disrupción celular de la biomasa que se atribuye a diferentes causas: cizallamiento de fluidos, turbulencia, velocidad de choque y la cavitación (Yap et al., 2015; Velazquez-Lucio et al., 2018; Jedrzejczyk et al., 2019). La cavitación hidrodinámica ocurre al pasar un líquido, o una suspensión, desde una gran cavidad transversal hacia una cavidad muy pequeña (válvula de mariposa) causando la constricción de la suspensión, y genera una caída de presión (por debajo de la presión de vapor) formando microburbujas que colapsan cuando la presión vuelve por encima de los valores normales de la presión de vapor, produce ondas de choque, aumentando la presión y temperatura, y causando disrupción celular (Yap et al., 2015; Velazquez-Lucio et al., 2018).

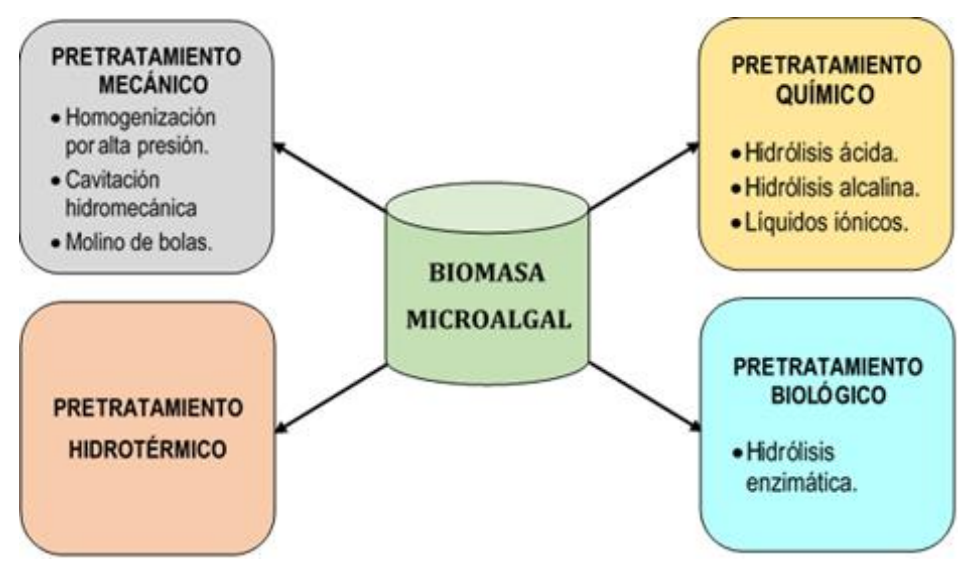

Figura 4. Técnicas de pretratamiento para biodegradación de la biomasa microalgal. 
El molino de bolas es muy utilizado para alterar las células de algunos microorganismos, causando disrupción celular; la efectividad puede afectarse por diferentes parámetros (velocidad de alimentación de la suspensión celular, velocidad de agitación, el diseño del agitador, el diámetro y el tamaño de las bolas, diseño de la cámara de molienda) siendo necesario considerar las interacciones del equipo con la biomasa microalgal de diferentes especies (Jedrzejczyk et al., 2019; Velazquez-Lucio et al., 2018; Fernandes et al., 2020).

b) Pretratamiento hidrotérmico es un método que permite hidrolizar los polisacáridos complejos en azúcares reductores, del almidón intracelular contenido en las paredes de las microalgas. Esta técnica trabaja a temperaturas que oscilan entre 60 y $180^{\circ} \mathrm{C}$, tiempos de reacción cortos por debajo de $60 \mathrm{~min}$, utilizando ácidos, álcalis, o solo agua como catalizador de reacción presenta grandes beneficios debido a la inexistencia de desechos tóxicos (Chen et al., 2013; Velazquez-Lucio et al., 2018). Este pretratamiento utiliza equipos específicos que pueden conducir a mayores costos de producción, no es necesario neutralizar las muestras tratadas, por lo que se considera un proceso ecológico. Sin embargo, es necesario realizar el proceso a altos valores de temperatura y presión (Chen et al., 2013; Velazquez-Lucio et al., 2018).

c) Pretratamiento químico es utilizado para disociar algunos compuestos orgánicos mediante ácidos fuertes, álcalis u oxidantes. Este pretratamiento modifica la estructura lignocelulósica de la biomasa microalgal, solubiliza los complejos de lignina y aumenta la hidrolisis (Agustini \& Febrian, 2019). Las soluciones ácidas y alcalinas, concentradas o diluidas, podrían usarse en condiciones hidrotermales, en tiempos de reacción más cortos, a costos más bajos y mayor capacidad para hidrolizar polímeros y oligosacáridos a monosacáridos (Jedrzejczyk et al., 2019; Velazquez-Lucio et al., 2018). Concentraciones más altas de los productos químicos disminuyen los tiempos de reacción, evitan el uso de enzimas, mientras que concentraciones bajas requiere valores más altos de temperatura y presión para lograr eficiencias de hidrólisis favorables (Chen et al., 2013). El uso de estos productos químicos a temperaturas altas implica formar compuestos de degradación muy concentrados, no deseables para el subsiguiente proceso de fermentación ya que inhiben los microorganismos involucrados en el proceso (VelazquezLucio et al., 2018; Agustini \& Febrian, 2019). El método basado en ácido emplea comúnmente ácido sulfúrico y ácido clorhídrico en concentraciones del 1 al 10\% y temperaturas entre 60 y $180^{\circ} \mathrm{C}$, promueve la degradación de la matriz de celulosa de la pared celular, la despolimerización de la hemicelulosa y la hidrólisis del almidón en moléculas simples para evitar la etapa de hidrólisis enzimática (Chen et al., 2013; Velazquez-Lucio et al., 2018). El método alcalino generalmente emplea hidróxido de sodio, caracterizado por crear reacciones de solvatación y saponificación, forma poros en la pared celular permitiendo que los compuestos intracelulares salgan de la célula, disminuyendo el tamaño de los polímeros de almidón, así como la cristalinidad de la celulosa y el almidón (Chen et al., 2013; Velazquez-Lucio et al., 2018; Agustini \& Febrian, 2019).

d) Pretratamiento biológico es una técnica respetuosa con el medio ambiente, ha dado buenos resultados debido a la ausencia de lignina en la estructura de las microalgas, la hidrolisis enzimática es uno de los enfoques prometedores del pretratamiento biológico, necesaria para la digestión de la biomasa microalgal; no encuentran más problemas asociados con la desactivación de enzimas, que es un paso esencial para lograr un método de pretratamiento eficiente y económico (Barati et al., 2021). La principal ventaja es su alta especificidad, sin requisitos de condiciones severas, y es fácil de realizar a escala industrial. La principal desventaja es el alto costo de las enzimas utilizadas, la hidrólisis se realiza empleando diferentes enzimas (celulasas, amilasas y amiloglucosidasas) que hidrolizan los polisacáridos de la pared celular (Enamala et al., 2018; Velazquez-Lucio et al., 2018; Fernandes et al., 2020).

Tabla 3

Tipos de microalgas utilizados en la elaboración de bioproductos y biocombustibles 3G

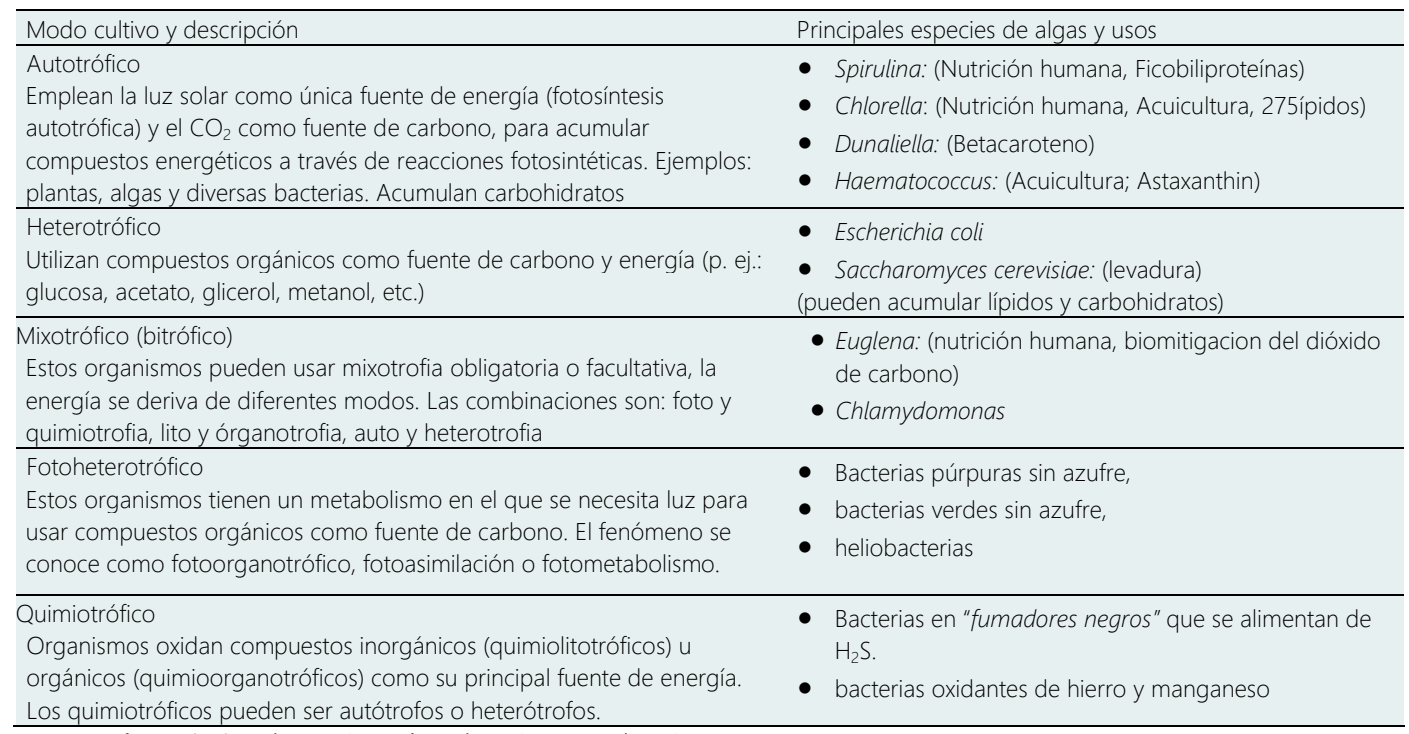

Nota: con información de Lackner (2015); Acién et al., 2021; Tiwari et al., (2019). 
Dependiendo del tipo de microalgas, su pared celular puede o no ser permeable a otros compuestos, por lo que a menudo no se requieren enzimas específicas para romperla, porque alcanzan a los carbohidratos intracelulares (Velazquez-Lucio et al., 2018). Finalmente, el proceso enzimático es el más simple en términos de equipamientos y no genera residuos químicos como subproductos de las reacciones, siendo más ecoamigable y no produce residuos que inhiban el proceso de fermentación del hidrolizado generado (Shokrkar et al., 2018; Kim et al., 2017).

9. Tendencias tecnológicas y retos en la producción de biocombustibles $3 \mathrm{G}$

Las microalgas ofrecen ilimitadas posibilidades para desarrollar una bioeconomía moderna, dada su flexibilidad metabólica y altas tasas de producción de biomasa. La bioeconomía es considerada como un paradigma nuevo y esencial para reducir la dependencia de los recursos naturales y responder a las amenazas ambientales que enfrenta actualmente nuestro planeta Tierra (Acién et al., 2021). En este sentido, se han producido diversos debates académicos y políticos sobre esta problemática, lo que ha llevado a los investigadores a centrar sus esfuerzos a obtener biomateriales y biocombustibles de tercera generación a partir de algas, que tienen un potencial significativo para contribuir al desarrollo de sectores emergentes, pero existe una preocupación creciente sobre su sostenibilidad general y su viabilidad. La biotecnología de microalgas es fundamental para lograr este objetivo en un futuro próximo. Las microalgas son capaces de convertir aguas residuales, $\mathrm{CO}_{2}$ y residuos orgánicos en una atractiva materia prima, biomasa microalgal, comercializable para diferentes usos (Vieira et al., 2021; Acién et al., 2021). La literatura sobre microalgas y biocombustibles de tercera generación está creciendo constantemente, numerosos estudios vienen realizándose desde hace cinco décadas. Las investigaciones actuales, con sólida base teórica y el soporte de sofisticadas herramientas biotecnológicas, están orientadas a optimizar los diversos factores en las diferentes etapas del proceso (aislamiento de cepas, cultivo y crecimiento, cosecha, pretratamiento, extraer lípidos y carbohidratos, diseño de reacciones y fotobiorreactores, extracción y purificación del producto y coproductos), como también la reutilización de los residuos y del impacto medioambiental etc. (Aro, 2016; Kahn et al., 2018; Tiwari et al., 2019; Mat Aron et al., 2020; Fan et al., 2020; Préat et al., 2020; Mennella et al., 2020; Vieira et al., 2021; Acién et al., 2021). La Tabla 3 muestra a los microorganismos más relevantes.

\subsection{El concepto de Biorrefinería}

El concepto de biorrefinería, basado en las rutas termoquímicas o bioquímicas, ofrece nuevas oportunidades de valorizar la biomasa, para sintetizar múltiples productos desde materias primas únicas o múltiples (Figura 5). El éxito de la industria de biocombustibles y bioenergía depende de la calidad y cantidad de biomasa microalgal disponible, así como de la capacidad rentable del proceso (Velazquez-Lucio et al., 2018; Bernaerts et al., 2018b; Harvey \& Ben-Amotz, 2020; Khoo et al., 2019)

La Tabla 4 reporta la composición y rendimiento de microalgas con buena capacidad.

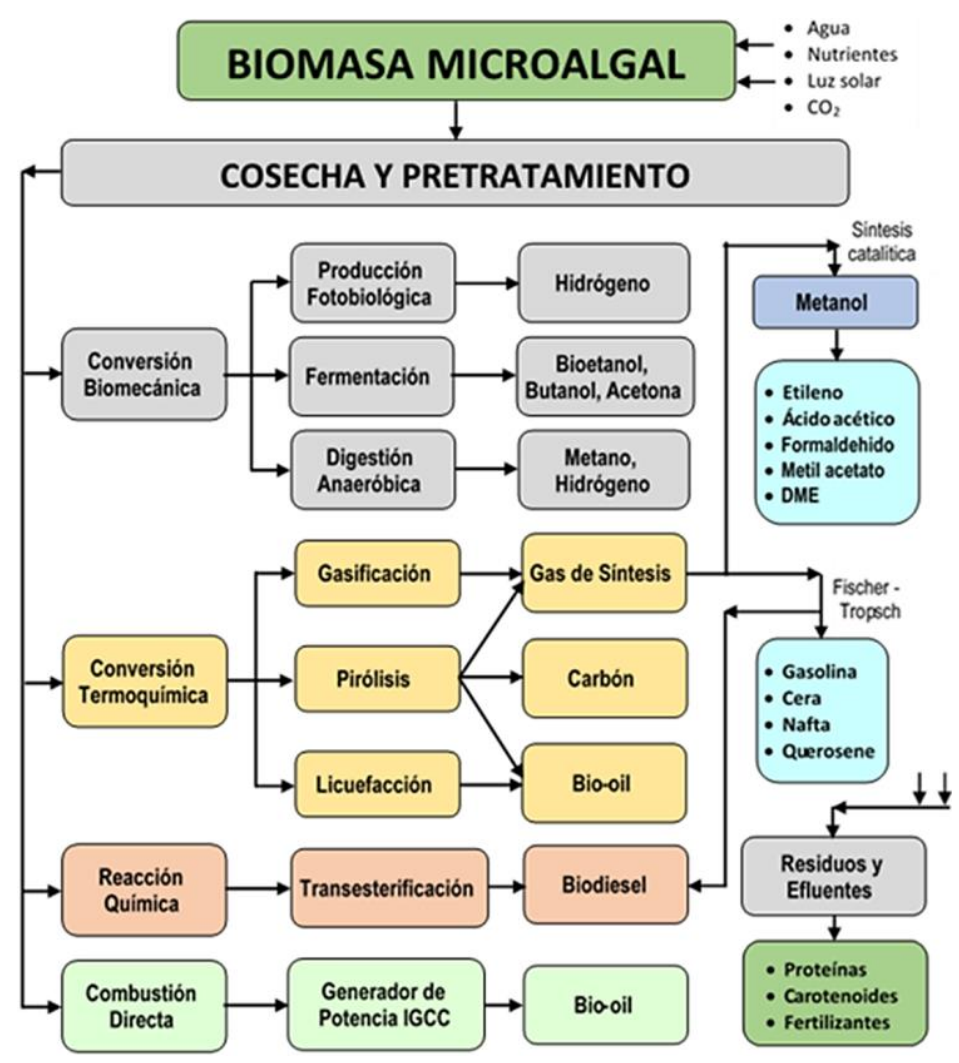

Figura 5. Enfoque de biorrefinería para producir biocombustibles, y coproductos, de microalgas. Elaborado con información de Lackner, (2015), Abdullah et al. (2019) y Khoo et al. (2019). 
Tabla 4

Análisis composicional de microalgas para producir biocombustibles y bioproductos

\begin{tabular}{|c|c|c|c|c|c|}
\hline Especie de microalgas & Proteínas & Carbohidratos & Lípidos & Rendimiento (g/L) & Ref. \\
\hline Anabaena cylindrica & $43-56 \%$ & $25-30 \%$ & $4-7 \%$ & - & (a) \\
\hline Arthrospira platensis & $45,0 \%$ & $44,0 \%$ & - & - & (b) \\
\hline Botryococcus braunii (A) & $39,9 \%$ & $18,5 \%$ & $34,4 \%$ & $(13,5 \%),(g)$ & (a) \\
\hline Botryococcus braunii (B) & $39,1 \%$ & $30,6 \%$ & $24,9 \%$ & $0.005(0,005 \%),(g)$ & (a) \\
\hline Chlamydomonas reinhardtii & $48,0 \%$ & $17,0 \%$ & $21,0 \%$ & $11,91(82 \%),(f)$ & (b) \\
\hline Chlorellab & $53,3 \%$ & $25,2 \%$ & $15,7 \%$ & - & (a) \\
\hline Chlorella sp. & $41,0 \%$ & $25,0 \%$ & $11,0 \%$ & $0,20(80 \%),(f)$ & (b) \\
\hline Chlorella vulgaris & $49,0 \%$ & $38,0 \%$ & $0,7 \%$ & $3,77(85),(f)$ & (b) \\
\hline Chlorella vulgaris & $51-58$ & $12-17 \%$ & $14-22 \%$ & 7,89 (89), (f) & (c) \\
\hline Dunaliella bioculata & $49,0 \%$ & $4,0 \%$ & $8,0 \%$ & - & (b) \\
\hline Dunaliella salina & $57,0 \%$ & $32,0 \%$ & $6,0 \%$ & $0,002(17,1 \%),(g)$ & $(\mathrm{c}),(\mathrm{g})$ \\
\hline Nannochloropsis granulate (A) & $33,5 \%$ & $36,2 \%$ & $23,6 \%$ & $0,061(29,6 \%),(g)$ & (a), (g) \\
\hline Nannochloropsis granulate (B) & $17,9 \%$ & $27,4 \%$ & $47,8 \%$ & $0,048(24,4 \%),(g)$ & $(\mathrm{a}),(\mathrm{g})$ \\
\hline Nannochloropsis oceanica & $10.0 \%$ & $33,0 \%$ & $34,0 \%$ & $0,142(29,7 \%),(g)$ & (b) \\
\hline Nannochloropsis sp. & - & - & $31-68 \%$ & $0,06(35,7 \%),(\mathrm{g})$ & (c), (g) \\
\hline Neochloris oleoabundans & $30,1 \%$ & $37,8 \%$ & $15,4 \%$ & $0,038(56 \%),(g)$ & (a), (g) \\
\hline Phaeodactylum & $39,6 \%$ & $25,2 \%$ & $18,2 \%$ & - & (a) \\
\hline Porphyridium aerugineum & $31,6 \%$ & $45,8 \%$ & $13,7 \%$ & - & (a) \\
\hline Porphyridium cruentum & $28-39 \%$ & $40-57 \%$ & $9-14 \%$ & $5.90(46 \%),(f)$ & $(c),(d)$ \\
\hline Prymnesium parvum & $28-45 \%$ & $25-33 \%$ & $22-38 \%$ & - & (b) \\
\hline Scendesmus dimorphous & $8-18 \%$ & $21-52 \%$ & $16-40 \%$ & $3,90(91.3 \%),(f)$ & (b) \\
\hline Tetraselmis chuii & $46,5 \%$ & $25,0 \%$ & $12,3 \%$ & $0,036(23 \%),(g)$ & (a), (g) \\
\hline Tetraselmis maculata & $52,0 \%$ & $15,0 \%$ & $3,0 \%$ & $0.043(14,7 \%),(g)$ & (b), (g) \\
\hline
\end{tabular}

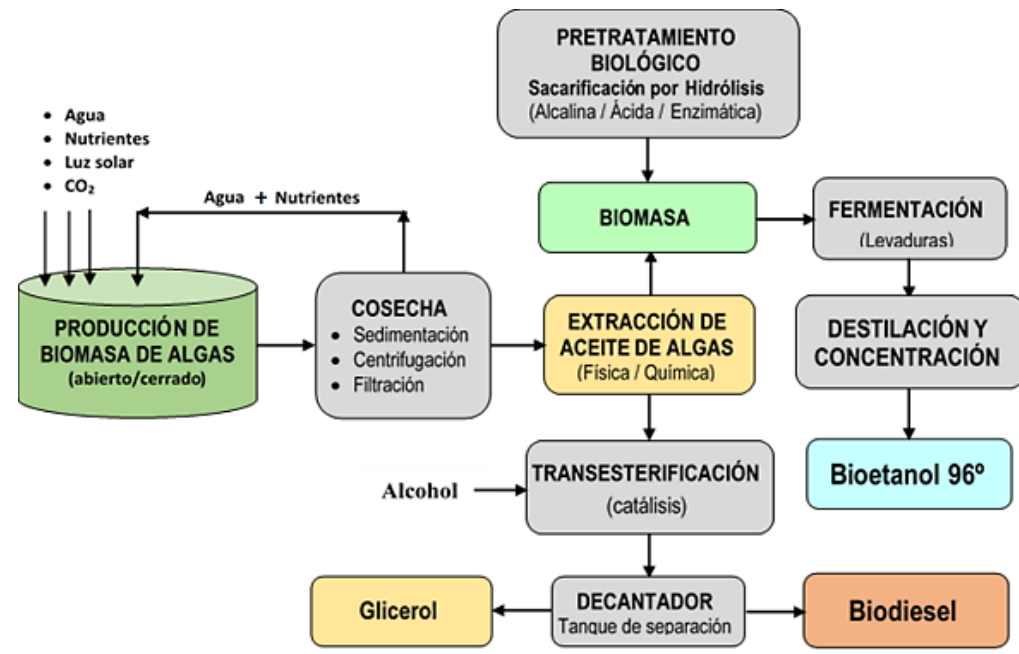

Figura 6. Esquema del proceso de producción de biodiesel y bioetanol desde biomasa microalgal.

La biorrefinería integra diferentes procesos de bioconversión para producir pequeñas cantidades de productos de alto valor (p.ej., químicos) y grandes cantidades de productos de bajo valor (p.ej., biocombustibles) (Figura 6), teóricamente maximiza el rendimiento de la materia prima y como posible solución para mejorar la economía del proceso (Karpagam et al.,
2021; Velazquez-Lucio et al., 2018; Préat et al., 2020). En una biorrefinería no es suficiente que la biomasa microalgal y los productos finales sean sostenibles y ecológicos, también es importante aplicar metodologías que minimicen el impacto medioambiental para garantizar un futuro próspero para las nuevas generaciones (World Bioenergy Association, 2019). 


\subsection{El biodiesel de tercera generación}

El biodiésel es un combustible alternativo renovable para motores diésel, que compite con el diesel de petróleo. El concepto de biodiesel de tercera generación surge después de aplicar métodos de recuperación bioenergética a diferentes tipos de biomasa microalgal, con alto contenido de lípidos. Es el biocombustible más investigado, la mayoría de los estudios describen diversas metodologías, ventajas y desventajas, y la viabilidad del proceso para obtener varios coproductos (Chisti, 2007; Alam et al., 2015; Lackner, 2015; Mathimani et al., 2015; Alam et al., 2015; Goncalves et al., 2016; Vinoth et al., 2019; Basile \& Dalena, 2019; Cui et al., 2020; Oostlander et al., 2020b).

Existen diversas especies de microalgas heterotróficas que pueden convertirse en lípidos, proteínas y aceites (Tiwari et al., 2019; Kim et al., 2015, 2017; Mussatto et al., 2010), tienen gran capacidad para acumular sus ácidos grasos, triglicéridos y glicolípidos de forma intracelular, esto involucra procesos de extracción de lípidos que encarecen la producción de biodiésel (Alam et al., 2015; Kim et al., 2015; Préat et al., 2020). El biodiesel se produce mediante Transesterificación, de los lípidos no polares TAG (Triacilglicerol) y FFA (ácidos grasos libres) del aceite de microalgas que reaccionan con un alcohol de cadena corta (principalmente metanol, aunque puede utilizarse etanol o propanol), en presencia de un catalizador ácido, alcalino o enzimático, para formar ácido graso (M) de Ésteres etílicos (Chisti, 2007; Préat et al., 2020). Un requisito importante, previo a la transesterificación, es la eliminación del alto contenido de humedad en la biomasa microalgal concentrada, que debe ser pretratada y bien secada para extraer el lípido. El agua disminuye el rendimiento en la producción de biodiésel durante el proceso de transesterificación (Enamala et al., 2018; Préat et al., 2020). En el caso de catálisis enzimática (Figura 7), el exceso de alcohol sería un gran problema porque inhibe la actividad enzimática y, por tanto, disminuye la actividad catalítica (Chisti et al., 2007).

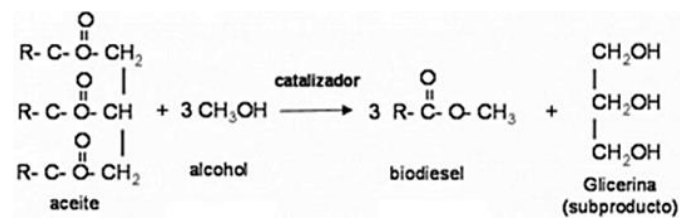

Figura 7. Reacción de catálisis enzimática en la producción de biodiesel.

Los ácidos grasos monoinsaturados (MUFA) son preferibles para producir biodiésel. El contenido del perfil lipídico de las microalgas depende principalmente de las condiciones de cultivo. Finalmente, el Biodiesel de microalgas no contiene azufre y funciona tan bien como el petróleo diésel, reduce las emisiones de material particulado, CO, hidrocarburos, y SOx. Sin embargo, las emisiones de NOx pueden ser mayores en algunos tipos de motor (Chisti, 2007; Aro, 2016; Martins et al., 2018).

\subsection{El bioetanol de tercera generación}

El bioetanol de tercera generación surgió para aprovechar la disponibilidad de nuevos recursos bioenergéticos de una biomasa no rígida y deslignificada, como las macroalgas o microalgas, para producir azúcares fermentables (Shokrkar et al., 2018; Chen et al., 2013; Bibi et al., 2017). Diversas especies de microalgas, generalmente autotróficas, son capaces de producir grandes cantidades de polisacáridos (celulosa en la pared celular y almidón en los plástidos) acumulados como carbohidratos (principal reserva de azúcar) en la biomasa microalgal, y puede extraerse para producir biocombustibles líquidos (etanol y biobutanol), mediante un proceso constituido por tres etapas: pretratamiento, sacarificación y fermentación (Chen et al., 2013; CuellarBermúdez et al., 2015). El pretratamiento tiene dos objetivos primordiales, descomponer la pared celular y modificar la estructura de los carbohidratos intracelulares para liberarlos, extracción del almidón y celulosa mediante herramientas mecánicas; la sacarificación, emplea hidrólisis enzimática para disolución de las paredes celulares, que poseen presencia insignificante o nula de lignina, proceso más simple comparado con el de la biomasa vegetal, en esta etapa se obtiene azúcares esenciales como glucosa y manosa (Cuellar-Bermúdez et al., 2015; Velazquez-Lucio et al., 2018); la fermentación de carbohidratos extraídos utiliza levaduras, como Saccharomyces cerevisiae (Chen et al., 2013; Bibi et al., 2017); en la separación y purificación, el etanol se drena del tanque de fermentación y es bombeado hacia la unidad de destilación (Tiwari et al., 2019).

El pretratamiento enzimático ampliamente utiliza celulasas, amilasas, glucoamilasas y alguna hemicelulasas; para obtener azúcares simples de la pared celular y los polisacáridos intracelulares (celulosa, hemicelulosa, etc.), con eficiencia de conversión hasta $84 \%$ del total de azúcares (Velazquez-Lucio et al., 2018).

Según manifiesta Cuellar-Bermúdez et al. (2015), la producción de etanol involucra cuatro reacciones principales: (a) proceso de glucólisis, donde una molécula de azúcar (glucosa $\mathrm{C}_{6} \mathrm{H}_{12} \mathrm{O}_{6}$ ), se descompone en dos moléculas de piruvato ( $\mathrm{CHCOCOO}^{-}$). La glucólisis provoca que dos moléculas de difosfato de adenosina (ADP) se reduzcan a dos moléculas de ATP y que dos moléculas de dinucleótido de nicotinamida y adenina $\left(N A D^{+}\right)$se reduzcan a dos moléculas de $\mathrm{NADH}$. Este proceso produce agua con iones de hidrógeno $\left(\mathrm{H}^{+}\right)$; (b) conversión de $\mathrm{CHCOCOO}^{-}$en acetaldehído $\left(\mathrm{CH}_{3} \mathrm{CHO}\right)$, catalizado por piruvato descarboxilasa, que produce $\mathrm{CO}_{2}$ y $\mathrm{H}^{+}$; (c) conversión del $\mathrm{CH}_{3} \mathrm{CHO}$ en ion etanol $\left(\mathrm{C}_{2} \mathrm{H}_{5} \mathrm{O}^{-}\right)$con la ayuda de la coenzima NADH que se produjo durante el proceso de glucólisis; y, (d) el anión etanol, que tiene propiedades similares al etanol convencional, es protonado por hidrógeno para producir etanol $\left(\mathrm{C}_{2} \mathrm{H}_{5} \mathrm{OH}\right)$. Durante el proceso de fermentación, se produce $\mathrm{CO}_{2}$ como subproducto $\left(\mathrm{C}_{6} \mathrm{H}_{12} \mathrm{O}_{6} \rightarrow 2 \mathrm{C}_{2} \mathrm{H}_{5} \mathrm{OH}+2 \mathrm{CO}_{2}\right)$.

Existen estudios de investigación que reportan la aplicación de diversas metodologías, y con diferentes rendimientos, para obtener bioetanol a partir de biomasa algal de diversas especies, tales como Sargazo sp., Laminaria sp., Chlorococcum sp., Prymnesium parvum, Gelidium amansii, Gracilaria sp., Spirogyra sp., Spirulina platensis, Trichoderma harzianum (Tiwari et al., 2019; Basile \& Dalena, 2019; Sánchez, 2017, 2019; Rempel et 
al.,2019; Bader et al., 2020; Bibi et al., 2017; Sanz-Smachetti et al., 2018; Li T. et al., 2019; Kim et al., 2017; Gallego et al., 2019; Hernández et al., 2015).

\subsection{El biogás de tercera generación}

Además de producir biocombustibles líquidos a partir de microalgas, utilizando los residuos de biomasa microalgal podría obtenerse biocombustibles gaseosos (metano y biohidrógeno), mediante proceso de fermentación aeróbico/anaeróbico (Mussatto et al., 2010; Chen et al., 2013; Tiwari et al., 2019). El biogás consiste principalmente en una mezcla de metano $\left(\mathrm{CH}_{4}\right)$ y dióxido de carbono $\left(\mathrm{CO}_{2}\right)$, con algunas trazas de gases como el sulfuro de hidrógeno (Kuila \& Sharma, 2018). Inicialmente la materia insoluble y las biomoléculas como carbohidratos, lípidos y proteínas se convierten en materia orgánica soluble por la acción enzimática de clostridios y estreptococos, seguida de acidogénesis y síntesis de ácidos grasos y alcohol. Las bacterias acetogénicas actúan sobre el alcohol y ácidos grasos volátiles, que conducen a la formación de metano y dióxido de carbono (Tiwari et al., 2019).

Los estudios han venido incrementándose, por codigestión anaeróbica han alcanzado alto rendimiento de metano (más del 60\%) y bajo contenido de azufre para evitar problemas de corrosión en el generador de energía, pero debe validarse a escala piloto (Chen et al., 2013; Bux \& Chisti, 2016; Rempel et al., 2019). En ausencia de pretratamiento, el rendimiento de metano se reduce aparentemente debido a la dureza de la pared celular de las algas (Bux \& Chisti, 2016). La codigestión consiste en mezclar sustratos alimentados a un digestor anaeróbico, la biomasa algal generalmente tiene alto contenido de nitrógeno (relación $\mathrm{C} / \mathrm{N}$ de 6 que es inferior al rango deseado de 25-32) en forma de proteínas que puede conducir a generar grandes niveles de amoníaco y la acumulación de ácidos grasos volátiles tóxicos. Por tanto, una biomasa rica en $\mathrm{N}$ requiere complementarse con cosustratos ricos en carbono para asegurar una buena conversión a metano (Bux \& Chisti, 2016). Es decir, los residuos de microalgas y materiales celulósicos (residuos agrícolas) se pueden co-digerir para equilibrar la relación C/N en el rango óptimo rango de 20: 1 y 25: 1 (Chen et al., 2013). La composición y el rendimiento del biogás están influenciados por factores como la temperatura, la composición de la materia prima, el pH y la tasa de alimentación (Tiwari et al., 2019). Se ha informado de la producción de biogás para Spirulina, Chaetomorpha litorea, Chlamydomonas reinhardtii, Scenedesmus obliquus, Ulva, Macrocystis pyrifera, Euglena y Durvillaea antarctica (Tiwari et al., 2019). El biogás puede ser un potencial sustituto del gas licuado de petróleo (GLP) y tiene varias ventajas: la recuperación es más sencilla, porque el producto (gas) se separa automáticamente de los sustratos. Produce abono orgánico enriquecido que puede complementar o incluso reemplazar fertilizantes químicos. Sin embargo, existen ciertas barreras ambientales y económicas que deben abordarse (Kuila \& Sharma, 2018; Tiwari et al., 2019).

El biohidrógeno es otro biogás, fuente de energía alternativa más prometedora porque es más limpio y eficiente, producido desde una biomasa algal a través de un proceso de dos etapas: (a) Biofotólisis (fijación de carbono), (b) Fotofermentación (digestión anaeróbica). La producción de hidrógeno a partir de algas puede ser una solución prometedora para abordar el problema de la contaminación ambiental (Kim et al., 2015). En cianobacterias o algas verdiazules, la formación de hidrógeno ocurre tanto en condiciones oxigenadas como anoxigénicas, mientras que en algas verdes la producción de hidrógeno se informa después de la adaptación a condiciones anoxigénicas (Tiwari \& Pandey, 2012).

\subsection{Perspectivas futuras}

La industria de biocombustibles de tercera generación, a pesar de los múltiples beneficios, tales como: (a) la materia prima (biomasa microalgal) y bioproductos (biocombustibles y coproductos), son renovables y sostenibles; (b) es una buena fuente de energía alternativa que compite con los combustibles fósiles; (c) son biodegradables y reducen el riesgo de contaminación del agua subterránea y del suelo; tiene como mayor desafío alcanzar la viabilidad técnico-económica del proceso y masificar su comercialización. El principal obstáculo en la comercialización de biocombustibles de algas es la economía del proceso, la cosecha equivale al 20-30\% del costo total (Chisti, 2007; Mussatto et al., 2010; Kim et al., 2015; Bux \& Chisti, 2016; Shokrkar, et al., 2018).

Aún subsisten cuestiones pendientes relacionadas con la eficiencia fotosintética y producción de biomasa, existe la posibilidad de utilizar $\mathrm{CO}_{2}$ de los gases de combustión para aumentar su velocidad de crecimiento, capacidad de modificar su composición bioquímica a través de optimizar el medio de cultivo (Cuellar-Bermúdez et al., 2015). Mediante una evaluación crítica debe comprenderse los diversos desafíos que enfrenta la producción de biocombustibles, investigando más sobre la estructura y composición de lípidos y carbohidratos de las especies algales, de la calidad y cantidad del aceite y/o azucares derivados del pretratamiento de la biomasa, calidad y cantidad de productos y coproductos derivados, la idoneidad de los biocombustibles debe estar vinculada con las tecnologías de motores disponibles, y prototipos futuros, para garantizar su accesibilidad. Actualmente, los biocombustibles son usados con ciertas modificaciones en los motores de combustión convencionales (Das \& Varanasi, 2019; Basile \& Dalena, 2019; Alam et al., 2015; Buxy \& Chisti, 2016; Guo et al., 2015).

La biomasa de algas posee un gran potencial para el proceso de biorrefinería, que es un enfoque atractivo y que tiene como principal desafío integrar las diversas tecnologías de conversión de biomasa, para la producción de biocombustibles y coproductos de valor agregado, debido a la variedad de algas con composiciones bioquímicas disponibles, que pueden ayudar a mejorar las perspectivas económicas de estas tecnologías, tema explorado intensamente en los últimos años para compensar los altos costos operativos. Es decir, un sistema de biorrefinería optimizado debe incluir los costos operacionales, la selección de cepas de algas robustas y la sostenibilidad del proceso. La evaluación del ciclo de vida de estos sistemas de biorrefinería de algas puede ayudar a comprender los posibles impactos positivos o 
negativos, considerando la sostenibilidad medioambiental, un impacto positivo sería el resultado de implementar la biorremediación de aguas residuales y la biofijación de CO2 por algas en el cultivo a gran escala podría atraer mucho más interés en las bioindustrias actuales (Khoo et al., 2019). Por tanto; el enfoque de la biorrefinería podría realizarse a plenitud en un futuro próximo a nivel comercial, contrarrestando los altos cosotos operacionales con tecnologías integradas que deben reducir etapas y con las ganancias obtenidas de los bioproductos.

Para hacer viable el proceso productivo de biocombustibles de tercera generación y bioproductos, es muy importante considerar las condiciones óptimas para un diseño de cultivo que permitan mejorar la acumulación de diferentes compuestos de interés (lípidos, carbohidratos, proteínas, pigmentos, etc.), la aplicación del agua de cultivo en el pretratamiento y el uso de solventes o catalizadores que sean amigables con el medio ambiente. A nivel molecular, se deben desarrollar enzimas más baratas y cepas industriales robustas que no solo puedan mejorar los rendimientos de producción sino también sostener los ambientes fisicoquímicos hostiles. El bajo contenido de energía del bioetanol y sus altas propiedades corrosivas pueden dañar fácilmente un motor de combustión (Velazquez-Lucio et al., 2018). La digestión anaeróbica de las algas es ciertamente prometedora, pero requiere un tratamiento previo de la biomasa y/o codigestión con cosustratos ricos en carbono (Bux \& Chisti, 2016). Desde el punto de vista económico, el proceso de digestión anaeróbica será rentable si está orientado a procesar los residuos de biomasa microalgal generados en la producción de biocombustibles de alta calidad, como bioetanol y biobutanol, o que sean mezclados con biomasa vegetal (residuos agrícolas), o que sea integrado en una biorrefinería de microalgas (Chen et al., 2013).

La literatura disponible, así como muy limitada, en el campo de los combustibles de cuarta generación, está orientada principalmente a encontrar estrategias para producir biomasa transgénica a partir de diversas especies de algas y microrganismos afines. Además, son muy escasos los estudios de investigación relacionados con los riesgos, para la salud y el medio ambiente, del uso de biomasa transgénica en la etapa productiva (es decir, en las etapas de cultivo, recolección y procesamiento), y que sirvan de base para discutir las mejores estrategias de mitigación asociadas.

\section{Conclusiones}

Las microalgas son una materia prima renovable, muy valorizados comercialmente, para producir biocombustibles líquidos y gaseosos, y coproductos. Es fundamental estudiar su metabolismo para desarrollar estrategias que permitan optimizar la productividad, de lípidos y/o carbohidratos, durante la etapa de cultivo y crecimiento de las microalgas, manipulando los factores operacionales claves (intensidad de luz, cantidad de nutrientes, suministro de $\mathrm{CO} 2$, temperatura, $\mathrm{pH}$ y salinidad). Asimismo, conocer las etapas subsiguientes del proceso: cosecha y pretratamiento. Es relevante el acoplamiento sinérgico de la producción de microalgas con el secuestro de carbono y las aplicaciones potenciales para mitigar los impactos ambientales asociados con el uso de la energía, las tecnologías para producir los biocombustibles y los coproductos de alto valor agregado.

El tipo de especies de microalgas, específicamente su morfología (composición de pared celular), tienen gran influencia en la eficiencia del proceso de producción de bioetanol de tercera generación. La mayor dificultad para viabilizar el proceso es la etapa de ruptura celular y liberación de azúcares fermentables de la biomasa algal. La hidrólisis enzimática, de los azúcares, ofrece muchas ventajas sobre la hidrólisis química con ácidos o álcalis, porque no requieren equipos caros, no se generan productos de degradación o compuestos tóxicos, y finalmente proporciona mayores rendimientos de carbohidratos simples. Para ser una alternativa tecnológica viable, el bioetanol debe presentar una alta ganancia neta de energía, tener beneficios ecológicos y ser económicamente competitivo. El éxito de la industria de los biocombustibles y bioenergía, desde la perspectiva de biorrefinería, depende de la calidad y cantidad de biomasa algal disponible, de la tecnología de conversión del tipo de combustible producido, y de la capacidad de utilizarlo de manera eficiente y rentable. La producción de biocombustibles, en una biorrefinería, puede ser comercialmente viable, si los subproductos de algas se generan y utilizan de manera óptima. En un futuro cercano se espera que el mercado de biocombustibles, y de sus coproductos, alcance solución realista con producción a gran escala, sostenible, sin afectar la seguridad alimentaria y el entorno medioambiental. La economía del proceso productivo necesita mejorar sustancialmente para tener competitividad, el nivel económico requerido puede ser alcanzable generando microalgas de bajo costo, mediante ingeniería genética y metabólica. La conclusión general del estudio refleja las valoraciones realizadas a las tecnologías existentes para producir biocombustibles de tercera generación, a partir de biomasa microalgal como materia prima de bajo costo y recurso energético renovable. El principal desafío es la integración de varias tecnologías de conversión de biomasa algal en una biorrefinería. Es necesario realizar más investigaciones para mejorar los contenidos de carbohidratos y perfiles lipídicos de ciertas cepas algales que tienen una alta productividad, para aumentar la sostenibilidad y economía del proceso. El biodiésel producido tiene un papel importante en el mantenimiento del medioambiente limpio, y se puede utilizar para el transporte. En la literatura reportan y recomiendan utilizar a dos especies de microalgas para producir bioetanol, Porphyridium cruentum (28-39\% proteína, 40-57\% carbohidratos y $9-14 \%$ lípidos) y Spirogira sp. (6-20\% proteína, 33-64\% carbohidratos y 11-21\% lípidos), quienes tienen las más altas concentraciones en carbohidratos y la ventaja de no contener residuos de lignina, convirtiéndose en recursos energéticos renovables bastante atractivos.

\section{ORCID}

M. Jimenez Escobedo (D) https://orcid.org/0000-0002-6042-2358

A. Castillo Calderón (D) https://orcid.org/0000-0001-9237-8542 


\section{Referencias bibliográficas}

Abdullah, B., Syed Muhammad, S. A. F., Shokravi, Z., Ismail, S., Kassim, K.A., et al. (2019). Fourth generation biofuel: A review on risks and mitigation strategies. Renewable and Sustainable Energy Reviews, 107, 37-50.

Acién, F. G., Reis, A., Wijffels, R. H., Barbosa, M., Verdelho, V., \& Llamas, B. (2021). The role of microalgae in the bioeconomy. New Biotech., 61, 99107.

Agustini, N. W., \& Febrian N., (2019). Hidrolisis biomassa mikroalga Porphyridium cruentum menggunakan asam $\left(\mathrm{H}_{2} \mathrm{SO} 4\right.$ dan $\left.\mathrm{HNO}_{3}\right)$ dalam produksi bioetanol. Jurnal Kimia dan Kemasan, 41(7), 1-10. http://dx.doi.org/10.24817/jkk.v41i1.3962

Alam, F., Mobin, S., \& Chowdhury, H. (2015). Third Generation Biofuel from Algae. Procedia Engineering, 105: 763-768.

AlgaeBase. (2020). Global algal database of taxonomic, nomenclatural and distributional information. Avalable online at https://www.algaebase.org/. Accesado 01 abril del 2020.

Aro, E. M. (2016). From first generation biofuels to advanced solar biofuels. Ambio, 45, 24-37.

Bader, A. N., Sanchez-Rizza, L., Consolo, V. F., \& Curatti, L. (2020). Efficient saccharification of microalgal biomass by Trichoderma harzianum enzymes for the production of etanol. Algal Research, 48, 101926

Baltz, R. H., Davies, J. E., \& Demain A. L. (2010). Manual of Industrial Microbiology and Biotechnology. 3th edition; American Society for Microbiology Press.

Barati, B., Fazeli, F., Parveen, Z., Rupani, R., \& Wang, S. (2021). Bacterial pretreatment of microalgae and the potential of novel nature hydrolytic sources. Environmental Technology \& Innovation, 27, 101362.

Barsanti, L., \& Gualtieri, P. (2014). ALGAE: Anatomy, Biochemistry and Biotechnology. $2^{\text {nd }}$ edition; Taylor \& Francis Group, CRC Press.

Basile, A., \& Dalena, F. (2019). Second and Third Generation of Feedstocks The Evolution of Biofuels. Elsevier Inc.

Bernaerts, T. M., Gheysen, L., Kyomugasho, C., Jamsazzadeh, K. Z., Vandionant, S., et al. (2018a). Comparison of microalgal biomasses as functional food ingredients: Focus on the composition of cell wall related polysaccharides. Algal Research, 32, 150-167.

Bernaerts, T. M., Kyomugasho, C., van Looveren, N., Gheysen, L., Foubert, I., et al. (2018b). Molecular and rheological characterization of different cel wall fractions of Porphyridium cruentum. Carbohydrate Polymers, 195, 542-550.

Bibi, R., Ahmad, Z., Imran, M., Hussain, S., Ditta, A., et al. (2017). Algal bioethanol production technology: A trend towards sustainable development. Renewable and Sustainable Energy Reviews, 7, 976-985.

British Petroleum. (2020). BP Statistical Review of World Energy 2020. Pureprint Group Limited. https://www.bp.com/en/global/corporate/energyeconomics/statistical-review-of-world-energy.html

Bux, F., \& Chisti, Y. (2016). Algae Biotechnology - Products and Processes. Springer International Publishing.

Carneiro, M., Cicchi, B., Maia, I. B., Pereira, H., Chini Zittelli, G., et al. (2020). Effect of temperature on growth, photosynthesis and biochemical composition of Nannochloropsis oceanica, grown outdoors in tubular photobioreactors. Algal Research, 49, 101923.

Chen, C-Y., Zhao, X-Q., Yen, H-W., Ho, S-H., Cheng, C-L., et al. (2013). Microalgae-based carbohydrates for biofuel production. Biochemical Engineering J., 78, 7-70.

Chisti, Y. (2007). Biodiesel from microalgae. Elsevier Inc. Biotechnology Advances, 25, 294-306.

Chowdhury, H., Loganathan, B., Mustary, I., Alam, F., \& Mobin, S. (2019). Algae for biofuels: The third generation of feedstock. In Basile A. y Dalena F. (Eds), Second and Third Generation of Feedstocks - The Evolution of Biofuels (Chap 12, pp. 323-344). Elsevier Inc.

Cuellar-Bermúdez, S. P., García-Pérez, J. S., Rittmann, B. E., \& Parra-Saldívar, R. (2015). Photosynthetic bioenergy utilizing CO2: an approach on flue gases utilization for third generation Biofuels. Journal of Cleaner Production, 98, 53-65

Cui, N., Feng, Y., Xiao, J., Ding, W., Zhao, Y., et al. (2020). Isolation and identification of a novel strain of Heveochlorella sp. and presentation of its capacity as biodiesel feedstock. Algal Research, 57, 102029.

Dalena, F., Senatore, A., Basile, M., Marino, D., \& Basile, A. (2019). From sugar to ethanol-from agricultural wastes to algal sources: An overview. In Basile A. y Dalena F., (Eds), Second and Third Generation of Feedstocks The Evolution of Biofuels (Chap 1, pp. 3-34). Elsevier Inc.

Das, D., \& Varanasi, J. (2019). Fundamentals of Biofuel Production Processes. Taylor \& Francis Group, CRC Press

de Farias, C. E., \& Bertucco, A. (2019). Bioethanol from Microalgal Biomass: A Promising Approach in Biorefinery. Brazilian Archives of Biology and Technology. 62, e19160816.

Dutta, K., Daverey, A., \& Lin, J. G. (2014). Evolution retrospective for alternative fuels: First to fourth generation. Renewable Energy, 69, 114-122.

Enamala, M. K., Enamala, S., Chavali, M., Donepudi, J., Yadavalli, R., et al. (2018). Production of biofuels from microalgae - A review on cultivation, harvesting, lipid extraction, and numerous applications of microalgae. Renewable Sustainable Energy Review, 94, 49-68

Fan, L., Zhang, H., Lia, J., Wang, Y., Leng, L., et al. (2020). Algal biorefinery to value-added products by using combined processes based on thermochemical conversion: A review. Algal Research, 47, 101819.

Fernandes de Souza, M., Almenara-Rodrigues, M.A., Pereira-Freitas, S., \& Pinto da Silva, B.E. (2020). Effect of milling and enzymatic hydrolysis in the production of glucose from starch-rich Chlorella sorokiniana biomass. Algal Research, 50, 101967.

Gallego, R., Martínez, M., Cifuentes, A., Ibañez, E., \& Herrero, M. (2019). Development of a Green Downstream Process for the Valorization of Porphyridium cruentum Biomass. Molecules, 24 (1564):7-13.

Gojkovic, Z., Lu, Y., Ferro, L., Toffolo, A., \& Funk, C. (2020). Modeling biomass production during progressive nitrogen starvation by North Swedish green microalgae Algal Research, 47, 101835.

Goncalves, E. C., Wilkie, A.C., Kirst, M., \& Rathinasabapathi, B. (2016) Metabolic regulation of triacylglycerol accumulation in the green algae: identification of potential targets for engineering to improve oil yield. Plant Biotechnology Journal, 14(8), 1-12.

Gong, Y., \& Huang, J. (2020). Characterization of four untapped microalgae for the production of lipids and carotenoids. Algal Research, 49, 101897.

Guo, M., Song, W., \& Buhain, J. (2015). Bioenergy and biofuels: History, status, and perspective. Renewable and Sustainable Energy Reviews, 42, 712725.

Harvey, P. J., \& Ben-Amotz, A. (2020). Towards a sustainable Dunaliella salina microalgal biorefinery for 9 -cis $\beta$-carotene production. Algal Research, $50,102002$.

Hernández, D., Riaño, B., Coca, M., \& García-González, M.C. (2015). Saccharification of carbohydrates in microalgal biomass by physical, chemical and enzymatic pre-treatments as a previous step for bioethanol production. Chemical Engineering Journal, 262, 939-945.

Hernández-Pérez, A., \& Labbé, J.I. (2014). Microalgas, cultivo y beneficios. Revista de Biología Marina y Oceanografía, 49(2), 157-173.

Khan, A., Fornes, O., Stigliani, A., Gheorghe, M., Castro-Mondragon, J. A., et al. (2018). JASPAR 2018: update of the open-access database of transcription factor binding profiles and its web framework. Nucleic Acids Research, 46(1), 260-266

Hong, S-J., \& Lee, C-G. (2015). Microalgal Systems Biology Through GenomeScale Metabolic Reconstructions for Industrial Applications. In Kim S-K. (Ed), Handbook of Marine Microalgae - Biotechnology Advances (Chap. 23, pp. 353-370). Academic Press.

Jedrzejczyk, M., Soszka, E., Czapnik, M., Ruppert, A. M., \& Grams, J. (2019). Physical and chemical pretreatment of lignocellulosic biomass. In Basile A. \& Dalena F. (Eds), Second and Third Generation of Feedstocks-The Evolution of Biofuels (Chap. 6, pp. 145-164). Elsevier Inc.

Jeong, G.-T., Kim, S. K., \& Oh, B. R. (2020). Production of fermentable sugars from Chlorella sp. by solid-acid catalyst. Algal Research, 57, 102044.

Karpagam, R., Kalimuthu Jawaharraj, K., \& Gnanam, R. (2021). Review on integrated biofuel production from microalgal biomass through the outset of transesterification route: a cascade approach for sustainable bioenergy. Science of The Total Environment, 766, 144236.

Kendir Çakmak, E., \& Ugurlu, A. (2020). Enhanced biogas production of red microalgae via enzymatic pretreatment and preliminary economic assessment. Algal Research, 50, 101979

Khan, M. I., Shin, J. H., \& Kim, J. D. (2018). The promising future of microalgae: current status, challenges, and optimization of a sustainable and renewable industry for biofuels, feed, and other products. Microbial Cell Factories, 17(7)

Khoo, C. G., Dasan, Y. K., Lam, M. K., \& Lee, K. T. (2019). Algae biorefinery: Review on a broad spectrum of downstream processes and products. Bioresource Technology, 292, (121964), 1-13.

Kim, M. H., Oh, H. C., \& Bae, H. J. (2017). Comparison of red microalgae (Porphyridium cruentum) culture conditions for bioethanol production. Bioresource Technology, 233, 44-50.

Kim, S-K. (Ed). (2015). Handbook of Marine Microalgae - Biotechnology Advances. Academic Press.

Kuila, A. \& Sharma, V. (Eds). (2018). Principles and Applications of Fermentation Technology. Scrivener Publishing.

Lackner, M. (2015). $3^{\text {rd }}$ Generation Biofuels: Bacteria and Algae as Sustainable Producers and Converters. In Lackner, M., Sajjadi, B., \& Chen, W.Y. (Eds), Handbook of Climate Change Mitigation and Adaptation (pp. 1-32). Springer

Li, T., Xu, J., Wu, H., Jiang, P., Chen, Z., \& Xiang, W. (2019). Growth and Biochemical Composition of Porphyridium purpureum SCS-02 under Different Nitrogen Concentrations. Marine Drugs, 17(124),1-16.

Luhani, Y., Rai, R., Prabhu, A. A., Maan, P., Hans, M., et al. (2020). Recent advances in bioethanol production from lignocelluloses: a comprehensive review with a focus on enzyme engineering and designer biocatalysts. Biofuel Research Journal, 28, 1267-1295.

Lutzu, G. A., Zhang, L., Zhang, Z., \& Liu, T. (2017). Feasibility of attached cultivation for polysaccharides production by Porphyridium cruentum. Bioprocess and Biosystem Engineering, 40, 73-83. 
Martins, A. O., Azimov, U., \& Burluka, A. (2018). Algae biofuel: Current status and future applications. Renewable and Sustainable Energy Reviews, 90,316-337.

Mat Aron, N. S., Khoo, K. S., Chew, K. W., Show, P. L., Chen, W., \& Nguyen, T. H. P. (2020). Sustainability of the four generations of biofuels - A review. International Journal of Energy Research, IF 3.741.

Mathimani, T., \& Mallick, N. (2018). A comprehensive review on harvesting of microalgae for biodiesel - Key challenges and future directions. Renewable and Sustainable Energy Reviews, 91, 1103-1120.

Mathimani, T., Beena, Nair, B., \& Rajith Kumar, R. (2015). Evaluation of microalga for biodiesel using lipid and fatty acid as a marker - A central composite design approach. Journal of the Energy Institute, 89, 3, 436446.

Medina-Cabrera, E. V., Rühmann, B., Schmid, J., \& Sieber, V. (2020). Characterization and comparison of Porphyridium sordidum and Porphyridium purpureum concerning growth characteristics and polysaccharide production. Algal Research, 49, 101931.

Mennella, L., Tosco, D., Alberti, F., Cembalo, L., Crescimanno, M., et al. (2020). Perspectives and challenges of small scale plant microalgae cultivation. Evidences from Southern Italy. Algal Research, 45, 101693.

Morales-Sánchez, D., Schulze, P.S.C., Kiron, V., \& Wijffels, R.H. (2020). Production of carbohydrates, lipids and polyunsaturated fatty acids (PUFA) by the polar marine microalga Chlamydomonas malina RCC2488. Algal Research, 50, 102016.

Moravvej, Z., Makarem, M. A., \& Reza Rahimpour, M. (2019). The fourth generation of biofuel. In Basile A., \& Dalena F., (Eds), Second and Third Generation of Feedstocks - The Evolution of Biofuels (Chap 20, pp. $553-$ 597). Elsevier Inc.

Mussatto, S.I., Dragone, G., Guimaraes, P.M., Silva, J.P., Carneiro, L.M., et al. (2010). Technological trends, global market, and challenges of bioethanol production. Biotechnology Advances, 28, 817-830.

Najjar, Y. S. H., \& Abu-Shamleh, A. (2020). Harvesting of microalgae by centrifugation for biodiesel production: A Review. Algal Research, 57, 102046.

Odjadjare, E. C., Mutanda, T., \& Olaniran, A. O. (2015). Potential biotechnological application of microalgae: a critical review. Critical Reviews in Biotechnology, 37(1), 37-52

Patil, S.A., Gildemyn, S., Pant, D., Zengler, K., Logan, B. E., \& Rabaey, K. (2015). A logical data representation framework for electricity-driven bioproduction processes. Biotechnology Advances, 33(6), 736-744.

Préat, N., Taelman, S. E., De Meester, S., Allais, F., \& Dewulfa, J. (2020). Identification of microalgae biorefinery scenarios and development of mass and energy balance flowsheets. Algal Research,45, 101737.

Rempel, A., de Souza, S. F., Margarites, A. C., Astolfi, A. L., Radis, S. R., et al. (2019). Bioethanol from Spirulina platensis biomass and the use of residuals to produce biomethane: An energy efficient approach. Bioresource Technology, 288, (121588), 1-8.
Sánchez, R. L. (2019). Estudios sobre la utilización de biomasa algal como materia prima alternativa para la producción de bioetanol. Tesis Doctoral, Universidad Nacional Mar del Plata, Argentina.

Sánchez, R. L., Sanz, S. M., Do Nascimento, M., Salerno, G. L., \& Curatti, L. (2017). Bioprospecting for native microalgae as an alternative source of sugars for the production of bioethanol. Algal Research, 22, 140-147.

Sanz-Smachetti, M. E., Coronel, C. D., Salerno, G. L., \& Curatti, L. (2020). Sucrose-to-ethanol microalgae-based platform using seawater. Algal Research, 45, 101733.

Shokrkar, H., Ebrahimi, S., \& Zamani, M. (2018). Enzymatic hydrolysis of microalgal cellulose for bioethanol production, modeling and sensitivity analysis. Fuel, 228, 30-38.

Singh, B., Bauddh, K., \& Bux, F., (Eds). (2015). Algae and Environmental Sustainability, (Developments in Applied Phycology 7). Springer India.

Singh, K. J., Singh, Y., Parveen, S., \& Singh, D. P. (2017). Microalgal Biofuels Flexible Bioenergies for Sustainable Development. In Singh R.S., Pandey A., \& Gnansounou E., (Eds), Biofuels - Production and Future Perspectives (Chap. 14, pp. 332-363). Taylor \& Francis Group, CRC Press.

Singh, R. S., Pandey, A., \& Gnansounou, E. (2017). Biofuels - Production and Future Perspectives. Taylor \& Francis Group, CRC Press.

Tiwari, A., Kiran, T., \& Pandey, A. (2019). Algae cultivation for biofue production. In Basile A. \& Dalena F. (Eds), Second and Third Generation of Feedstocks-The Evolution of Biofuels (Chap. 14, pp. 383-403). Elsevier Inc.

Velazquez-Lucio, J., Rodríguez-Jasso, R., Colla, L., Sáenz-Galindo, A., Cervantes-Cisneros, D., et al. (2018). Microalgal biomass pretreatment for bioethanol production: a review. Biofuel Research Journal, 17, 780791.

Vieira de Mendonça, H., Assemany, P., Abreu, M., Couto, E., Martins M. A., et al. (2021). Microalgae in a global world: New solutions for old problems? Renewable Energy, 165, Part 1, 842-862.

Vinoth, J. V. A., Bharathirajaa, B., Vijayakumara, B., Arokiyarajc, S., lyyappana, J., \& Praveen Kumar, R. (2019). Biodiesel production from microalgae Nannochloropsis oculata using heterogeneous Poly Ethylene Glycol (PEG) encapsulated ZnOMn2+ nanocatalyst. Bioresource Technology, 282, 348-352.

Webb, A. (2016.) A brief history of biofuels: From ancient history to today. In BioFuelNet.

Webb, A., \& Coates, D. (2012). Biofuels and Biodiversity. Secretariat of the Convention on Biological Diversity. Montreal, CBD Technical Series No. $65,69 \mathrm{p}$.

World Bioenergy Association. (2019). WBA Global Bioenergy Statistics 2019. http://www.worldbioenergy.org

Yap, B. H. J., Dumsday, G. J., Scales, P. J., \& Martin, G. J. O. (2015). Energy evaluation of algal cell disruption by high pressure homogenisation. Bioresource Technology, 184, 280-285. 